\title{
$N$-glycosylation modulates enzymatic activity of Trypanosoma congolense trans-sialidase
}

\author{
Jana Rosenau*1, Isabell Louise Grothaus ${ }^{* 1,2}$, Yikun Yang ${ }^{1,3}$, Lucio Colombi Ciacchi², \\ Sørge Kelm ${ }^{1}$, Mario Waespy ${ }^{1}$ \\ *Shared co-first authorship \\ ${ }^{1}$ University of Bremen, Centre for Biomolecular Interactions Bremen, Faculty for \\ Biology and Chemistry, 28359 Bremen, Germany \\ ${ }^{2}$ University of Bremen, Hybrid Materials Interfaces Group, Faculty of Production \\ Engineering, Bremen Center for Computational Materials Science, Center for \\ Environmental Research and Sustainable Technology (UFT), and MAPEX Center for \\ Materials and Processes, 28359 Bremen, Germany \\ ${ }^{3}$ Innovation Research Institute of Traditional Chinese Medicine, Shandong University \\ of Traditional Chinese Medicine, Jinan 250355, Shandong, China
}

\section{Running title: $N$-glycosylation modulates TconTS activity}

\section{Keywords}

proteoglycan, molecular dynamics, mass spectrometry (MS), enzyme kinetics, circular dichroism, $\mathrm{N}$-glycosylation, protein-glycan interactions, trans-sialidases, Trypanosoma

\begin{abstract}
Trypanosomes cause the devastating disease trypanosomiasis, in which the action of trans-sialidase (TS) enzymes harbored on their surface is a key virulence factor. TS are highly $N$-glycosylated, but the biological functions of the glycans remain elusive. In this study, we investigated the influence of $\mathrm{N}$-glycans on the enzymatic activity and structure stability of TconTS1, a recombinant TS from the African parasite Trypanosoma congolense. MALDI-TOF MS revealed that eight asparagine sites were glycosylated with high-mannose type $N$-glycans. Deglycosylation of TconTS1 led to a 5 -fold decrease in substrate affinity but to the same conversion rate relative to the untreated enzyme. After deglycosylation, no changes in secondary structure elements were observed in circular dichroism experiments. Molecular dynamics simulations revealed interactions between the highly flexible $N$-glycans and some conserved amino acids belonging to the catalytic site. These interactions led to conformational changes, possibly enhancing substrate accessibility and promoting enzyme/substrate complex stability. The here-observed modulation of catalytic activity via the $N$-glycan shield may be a structure-function relationship intrinsic of several members of the TS family.
\end{abstract}




\section{Introduction}

Glycosylation, or the covalent attachment of carbohydrates to the polypeptide chain of proteins, is the most diverse protein modification in eukaryotic cells. One type of protein glycosylation is the $N$-linked glycosylation, the attachment of an oligosaccharide to an asparagine residue ( $\mathrm{N}$-glycan) in the $\mathrm{N}-\mathrm{X}-\mathrm{S} / \mathrm{T}$ motif. $\mathrm{N}$-glycans are branched, tree-like polysaccharide structures built up of different monosaccharide units, which are linked via different glycosidic bonds.

$N$-glycans are involved in folding and stability of proteins, regulate protein functions, represent target structures for lectins or antibodies, and can function as mediators of cell-matrix interactions and cell-cell recognition and communication (1-3). Recent studies of $\mathrm{N}$-glycans include molecular dynamics simulations of the SARS-CoV-2 spike protein's glycan shield, the characterization of the glycosylated infectious bronchitis virus spike protein as well as the heavily glycosylated receptor CD22 on B-cells by means of wet lab-based approaches (4-6). N-glycosylation has also been suggested to affect the secretion and thermal stability of enzymes, and to alter their kinetic activity (1).

In this study, we use the highly $N$-glycosylated enzyme trans-sialidase (TS) as a model to investigate the influence of $N$-glycans on enzymatic activity, thermal stability, and structural conformation, combining kinetic and mass spectrometry (MS) data with molecular dynamics simulations. TS are unusual enzymes expressed by different species of the parasitic genus Trypanosoma $(T$.$) . This includes human pathogens$ causing Chagas disease in South America ( $T$. cruzi) and sleeping sickness in Africa ( $T$. brucei), as well as animal pathogens being responsible for the animal African trypanosomiasis (T. brucei, $T$. congolense, $T$. vivax) (7-10). The glycosylphosphatidylinositol (GPI)-anchored enzymes preferentially transfer $\alpha 2,3-$ linked sialic acids (Sia) from host-cell glycoconjugates to $\beta$-galactose residues of glycoproteins present on the parasite's surface, thus creating a new $\alpha 2,3$-glycosidic linkage $(7,8,11)$. This surface sialylation has different beneficial functions for the parasite, which is unable to synthesize Sia de novo. In particular it promotes survival in the insect vector and enables to escape the host's immune system (12-16). Thus, TS are important virulence factors and represent promising drug targets and vaccine candidates to combat the fatal diseases caused by trypanosomes.

The enzymatic mechanisms and the biological functions of TS have been under study for many years, although little attention has been drawn to the influence of posttranslational modifications such as glycosylation (17-22).

Interestingly, high-mannose type $N$-glycans have been reported for many TS indirectly by concavalin $A(C o n A)$ purification $(8,23,24)$. It has been postulated that these glycans are involved in TS oligomerization (25). However, its influence on enzyme activity is still debated $(17,18,21,22)$. Previous experiments were performed with recombinant TS expressed by Pichia (P.) pastoris, which produces hypermannosylated $N$-glycans $(21,22)$. However, trypanosomal surface proteins were reported to harbor shorter high-mannose type $N$-glycans (26-31). No differences in Sia transfer activity were observed between glycosylated and deglycosylated recombinant TS expressed by $P$. pastoris $(21,22)$. 
We investigated the role of high-mannose type $N$-glycans using recombinant TS1 from the animal pathogen $T$. congolense (TconTS1) (32). TconTS1 is expressed by procyclic insect-infective trypanosomes as well as bloodstream-form trypanosomes in mammalian hosts, and is involved in desialylation of erythrocytes, which contributes to anemia (33, 34). Like all TS, TconTS1 consists of an $N$-terminal catalytic domain (CD) responsible for the transfer of Sia, and of a C-terminal lectin-like domain (LD) whose biological function remains unclear. Recently, we demonstrated that TconTS-LD can modulate enzymatic activity (35). CD and LD are connected via an $\alpha$-helix (Fig. 1) (17, 18, 32). The $N$-terminus includes a signal sequence, whereas the $\mathrm{C}$-terminus comprises a potential GPI anchor attachment site (32). So far, 17 TconTS-like genes have been described for $T$. congolense, from which 11 can be grouped into the TconTS1 family due to their high amino acid sequence similarity (>96 \%). TconTS1b was chosen in this study, because it possesses one of the highest enzyme activities $(32,36)$ and is simply called TconTS1 onwards.

An important structural feature of TconTS1 are the predicted nine $N$-glycosylation recognition sequences (Figure 1 ), distributed across both the $\operatorname{CD}$ and $\operatorname{LD}(25,32)$. It is noteworthy that TS sequences from African trypanosomal species contain a higher number of $N$-glycosylation sites (6-9) compared to those of species from SouthAmerican trypanosomes (2-5) including the structural closely related sialidase (SA) from $T$. rangeli $(10,21,32,36-39)$.

To investigate $\mathrm{N}$-glycosylation induced structure-function effects, we expressed recombinant TconTS1 in CHO Lec1 fibroblasts. This glycosylation mutant mainly produces $\mathrm{N}$-glycans of the composition $\mathrm{Man}_{5} \mathrm{GlcNAc}_{2}$ which is similar to the highmannose type $\mathrm{N}$-glycans described for African trypanosomes (Man ${ }_{5-9} \mathrm{GlcNAc}_{2}$ ) (26$31,40,41)$. The actual presence of $N$-glycans at the putative $N$-glycosylation sites was analyzed via MALDI-TOF MS. Enzyme activities of glycosylated and Endoglycosidase $\mathrm{H}\left(\mathrm{EndoH}_{\mathrm{f}}\right)$-treated TconTS1 were then compared in activity assays. Circular Dichroism spectroscopy was used to compare the secondary structures and stabilities of glycosylated versus deglycosylated TconTS1. Finally, molecular dynamics (MD) simulations were performed to analyze potential protein-glycan and glycan-glycan interactions altering the dynamics of amino acids in close proximity to the CD.

\section{Results}

\section{TconTS1 is heavily glycosylated with high-mannose type $\mathrm{N}$-glycans}

To characterize $\mathrm{N}$-glycosylation of TconTS1 in detail, we expressed TconTS1 in CHO Lec1 cells (Fig. S1A, S2) (32). High-mannose type $N$-glycans of the recombinant protein could be detected in lectin blots using ConA (Fig. 2A). For deglycosylation, enzymatical removal of $\mathrm{N}$-glycans, TconTS1 was treated with $\mathrm{EndoH}_{\mathrm{f}}$, called DTconTS1 in this study. A different gel electrophoresis migration profile and reduced ConA binding was observed for D-TconTS1 (Fig. 2A). However, deglycosylation was not complete, as a faint band was still visible in ConA blots. Even further addition of EndoH $_{f}$ or increased incubation time did not result in complete deglycosylation, potentially suggesting poor accessibility of some glycans to $\mathrm{EndoH}_{\mathrm{f}}$. Thus, this partially deglycosylated protein was used in the following experiments. 
TconTS1 harbors nine potential $N$-glycosylation sites, five in the $\mathrm{N}$-terminal $\mathrm{CD}$ and four in the LD. MALDI-TOF MS experiments were performed to identify $N$-glycan structures attached at potential $N$-glycosylation sites. In order to analyze TconTS1 with MALDI-TOF MS, it was necessary to cut the enzyme in shorter peptide and glycopeptide fragments via protease digestion using either trypsin or chymotrypsin. The resulting fragments were separated by their mass-to-charge ratio. Glycosylated peptides have a higher mass compared to their unglycosylated counterparts due to the molecular mass of the attached glycan. Glycopeptide analysis via MALDI-TOF MS is challenging, because they have a lower ionization efficiency than unglycosylated peptides (42). Therefore, different analyses were performed with varying sample preparations to unravel the complete $\mathrm{N}$-glycosylation profile of TconTS1. A summarizing evaluation is given in Table 1. In a first approach, generated peptides of TconTS1 were analyzed in order to identify all peptide fragments with potential $\mathrm{N}$ glycosylation sites in their glycosylated or unglycosylated state. Although glycopeptides are usually under-represented in MALDI-TOF mass spectra of the entire protein, this approach confirmed high-mannose type $\mathrm{N}$-glycans at six out of the nine positions with the $N$-glycosylation consensus sequence $\mathrm{N}-\mathrm{X}-\mathrm{S} / \mathrm{T}$ (N45, N113, N206, N240, N281, N693; exemplary spectrum shown in Fig. S3A). Interestingly, five of them were located in the CD.

As reported for protein expression in the glycosylation mutant cell line CHO Lec1, Nglycans were almost exclusively composed of Man ${ }_{5} \mathrm{GlcNAc}_{2}$. Glycopeptides harboring the potential $\mathrm{N}$-glycosylation sites $\mathrm{N} 45$ and N281 were only found with high-mannose type $\mathrm{N}$-glycans, whereas peptides containing N113, N206, N240 and N693 were detected both with and without $N$-glycans, indicating $N$-glycosylation heterogeneity at these sites. For the peptide containing the first potential glycosylation site in the LD (N625), we only detected the mass corresponding to the ungycosylated peptide, suggesting that this site is not glycosylated.

In the following approach, glycopeptides were separated from unglycosylated peptides using ConA adsorbent. The removal of unglycosylated peptides reduced the complexity of the MALDI-TOF mass spectra and confirmed high-mannose type $\mathrm{N}$ glycans at the six $\mathrm{N}$-glycosylation sites identified in the first approach (N45, N113, N206, N240, N281, N693; exemplary spectrum shown in Fig. 2B). Additionally, one further N-glycan was identified at position N657 in the LD. The approach also unveiled a number of glycans other than Man ${ }_{5} \mathrm{GlCNAc}_{2}$ at position N206, namely Man ${ }_{6} \mathrm{GlcNAc}_{2}$ and $\mathrm{Man}_{8} \mathrm{GlcNAc}_{2}$.

In a third experimental set-up, the $\mathrm{EndoH}_{\mathrm{f}}$-deglycosylated D-TconTS1 was analyzed after protease digestion. This approach further allowed the identification of $N$ glycosylation sites since $\mathrm{EndoH}_{f}$ catalyzes the hydrolysis of the $\beta-1,4-$ glycosidic linkage in the chitobiose core of high-mannose type $N$-glycans and leaves one GlcNAc unit attached to the glycopeptide. Glycopeptides harboring a $N$-glycosylation site and a residual GICNAc in these preparations are therefore an additional indication of $\mathrm{N}$ glycosylation sites carrying high-mannose type $\mathrm{N}$-glycans. We were able to verify all $N$-glycosylation sites which were identified in the previous approaches (exemplary spectrum shown in Fig. S3B). However, results for two glycosylation sites (N206, N281) were ambiguous since masses corresponding to the glycopeptides with an additional GlcNAc were also detected in the untreated TconTS1. 
bioRxiv preprint doi: https://doi.org/10.1101/2021.12.13.472379; this version posted December 14, 2021. The copyright holder for this preprint (which was not certified by peer review) is the author/funder, who has granted bioRxiv a license to display the preprint in perpetuity. It is made available under aCC-BY 4.0 International license.

Additionally, we identified $N$-glycosylation sites with this approach (N113, N206, N693) that exhibited high-mannose type $\mathrm{N}$-glycans even after $16 \mathrm{~h}$ of EndoH $\mathrm{f}_{\mathrm{f}}$-treatment (Table 1), consistent with the ConA blot experiment (Fig. 2A).

All three different approaches revealed a predominant $N$-glycosylation in TconTS1-CD and allowed for a detailed analysis of the composition of $\mathrm{N}$-glycans at both constant and variable $N$-glycosylation sites (Table 1 ).

In none of these experiments we could identify a leucine-rich peptide containing the $\mathrm{N}$ glycosylation consensus sequence N-E-S (662-664), neither in the glycosylated nor in the unglycosylated form. The peptide was not detectable also when the mass lists were analyzed for different glycans and post-translational modifications. Among the many different proteases which are suitable for MALDI-TOF MS analysis, the leucine-rich fragment only contained cleavage sites for chymotrypsin. However, the protease cleaves at the carboxyl side of different amino acids (Y, F, W, L, M), but the cleavage efficiency is rather low after leucine and methionine. It is therefore possible that the leucine-rich fragment was not sufficiently cleaved by chymotrypsin and thus too large to be detected. Another possibility is that the fragment has been digested into many different peptides in quantities below the detection limit.

\section{N-glycosylation of TconTS1 influences the acceptor substrate affinity of the Sia transfer reaction}

To test the impact of $\mathrm{N}$-glycosylation on enzyme activity, we performed activity assays with D-TconTS1 and a control TconTS1 as reference. The control TconTS1 was treated at similar conditions as used in the deglycosylation protocol, including an incubation step for 16 hours at $37^{\circ} \mathrm{C}$. Fetuin and lactose were used as Sia donoracceptor pairs, as described $(32,36)$. The transfer reaction product 3 'sialyllactose (3'SL) was analyzed via high performance anion exchange chromatography (HPAEC) with pulsed amperometric detection (PAD). The method allows for the separation and detection of the educt lactose, the product 3'SL, and the side product $N$ acetylneuraminic acid (Neu5Ac). The latter potentially occurs from hydrolytic activity of TS releasing free Neu5Ac from generated 3'SL. Incubation times of 30 minutes and $600 \mu \mathrm{M}$ fetuin-bound Sia were used in these experiments. The lactose concentrations were varied to determine the kinetic parameters $\mathrm{K}_{M}$ and $\mathrm{V}_{\text {max }}$.

Under the same reaction conditions, D-TconTS1 produced less 3'SL than TconTS1 (Fig. 3A). However, the calculated $\mathrm{V}_{\max }$ for the acceptor lactose using $600 \mu \mathrm{M}$ fetuinbound Sia as donor substrate was identical within the error range for both enzymes and amounted to $2.4 \mu \mathrm{mol} 3$ 'SL/(min x mg enzyme) (Fig. 3B). This implies that TconTS1 produces the same amount of 3'SL per time unit at high acceptor concentrations irrespective of its glycosylation state. However, the $\mathrm{K}_{\mathrm{M}}$ values for lactose differed between TconTS1 $(1.7 \mathrm{mM})$ and D-TconTS1 $(9.0 \mathrm{mM})$, indicating a 5fold lower acceptor substrate affinity for the deglycosylated enzyme. The $K_{M}$ of TconTS1 is identical to the $\mathrm{K}_{\mathrm{M}}$ published by Koliwer-Brandl et al. (32) $(1.7 \mathrm{mM})$. Differences between previously reported $V_{\max }$ values for TconTS1 $(4.1 \pm 0.1 \mu \mathrm{mol}$ 3'SL/(min x mg enzyme) (32) might be explained by different enzyme preparations or by the fact that the glycosylated TconTS1 control in this study was treated equally to the deglycosylated enzyme including an incubation step for $16 \mathrm{~h}$ at $37^{\circ} \mathrm{C}$ (see above). 
bioRxiv preprint doi: https://doi.org/10.1101/2021.12.13.472379; this version posted December 14, 2021. The copyright holder for this preprint (which was not certified by peer review) is the author/funder, who has granted bioRxiv a license to display the preprint in perpetuity. It is made available under aCC-BY 4.0 International license.

\section{The presence or absence of high-mannose type $N$-glycans does not alter the secondary structure of TconTS1}

Once we were able to determine TconTS1's $N$-glycan profile and its influence on the enzyme activity, we addressed the question if $N$-glycans are able to modulate the enzyme stability. Since the presence of $N$-glycans can impact the protein's function via altering the protein structure (43), we performed circular dichroism experiments to investigate the influence of $\mathrm{N}$-glycans on TconTS1's secondary structure.

Circular dichroism spectra of TconTS1 and D-TconTS1 were analyzed under similar conditions used for the enzyme activity measurements $\left(35^{\circ} \mathrm{C}\right)$ (Fig. 4A). The recorded spectra do not show any significant difference over the recorded wavelength range, indicating that both enzymes share the same common secondary structure. In fact, calculated secondary structural elements were identical in both cases with $37 \%$ of $\beta$ sheets, $13 \%$ of $\alpha$-helices, $11 \%$ of turns and $39 \%$ of unstructured (other) components in both cases (Table S1).

Spectra recorded during temperature-ramping experiments revealed a high heat stability, as both TconTS1 and D-TconTS1 still possessed intact secondary structural elements up to $95^{\circ} \mathrm{C}$ (Fig. 4C/D). The variation of the spectra intensity in the range between 190 and $210 \mathrm{~nm}$ during heating indicates a partial unfolding, taking place between $60^{\circ} \mathrm{C}$ and $70^{\circ} \mathrm{C}$, with a transition temperature $\left(\mathrm{T}_{\mathrm{M}}\right)$ of about $62^{\circ} \mathrm{C}$ in both proteins (Fig. 4B).

In conclusion, the circular dichroism experiments indicated that the altered substrate affinity observed for D-TconTS1 did not originate from changes in the protein's secondary structure, which presents the same secondary element distribution and the same heat stability (as quantified by the melting temperature $\left(T_{M}\right)$ for partial unfolding) for both glycosylation states. However, $N$-glycosylation-induced changes of the tertiary structure cannot be excluded because they do not influence the circular dichroism spectra in the measured wavelength region.

\section{Functional importance of TconTS1 $\mathrm{N}$-glycans revealed by molecular dynamics simulations}

\subsection{The $\mathrm{N}$-glycan shield}

Molecular dynamics simulations can facilitate the study of mechanisms at the atomistic level and were performed to obtain an in-depth picture of $N$-glycan-protein interactions in TconTS1. Due to the lack of experimentally derived structures for TconTS enzymes, homology models were constructed on the basis of $T$. rangeli sialidase (TranSA) and T. cruzi TS (TcruTS). Although TconTS1 only has an amino acid sequence identity of $48 \%$ compared to TcruTS, both reveal an overall high structural similarity and only differ in three amino acids reported to be important for TS activity (32). In order to generate a $\mathrm{N}$-glycosylated structure model of TconTS1, Man ${ }_{5} \mathrm{GlcNAc}_{2}$ glycans were attached at positions N45, N113, N206, N240, N281 and N693, as identified by MALDITOF MS. In this model, all potential $N$-glycosylation sites are glycosylated in the CD, whereas only one out of four potential sites is glycosylated in the LD.

At first, standard MD simulations have been performed for TconTS1 and D-TconTS1 without bound substrates, in order to observe the dynamical behavior of the covalently 
linked $\mathrm{N}$-glycans. Six out of nine asparagine residues in the motif $\mathrm{N}-\mathrm{X}-\mathrm{T} / \mathrm{S}$ are located at the tail of loop regions (Fig. 5A), which are mostly part of turns or coils and framed by $\beta$-sheet regions (Fig. S4A). The terminal position and flexibility of these structural elements allow for large motion amplitudes and internal flexibility of the $\mathrm{N}$-glycan trees. These movements enable interactions among glycans in structural proximity, for instance hydrogen bonds between the trees at positions N113 and N240 (Fig. 5B), notwithstanding their distance in the protein sequence. Furthermore, an overlay of the averaged glycan distribution recorded every 5 ns during the simulation (Fig. 5C/D) revealed a dense glycan coverage (shielding) of the protein, especially in the CD and except for the direct entrance to the active site (Fig. 5D).

\subsection{Dynamics of conserved amino acids in TconTS1-CD without substrate}

Interactions of $\mathrm{N}$-glycans with important and highly conserved amino acids involved in the catalytic activity of TconTS1 $(32,44)$ were analyzed over the 500 ns MD trajectories. We especially focused on residues involved in catalysis (D150, E324, Y438) and substrate binding (R126, R144, Y211, W212, R339, Y408, R410).

In TconTS1, D150 was observed to shift from the interior of the active site (Fig. 6A) towards an exterior position (Fig. 6B), increasing its distance from R410, which was stationary within the active site (Fig. 6C). Interestingly, as a consequence of this shift, a hydrogen bond formed between D150 and the N206 glycan (Fig. 6C/D). Detailed analysis revealed that this process was initiated by hydrogen bond formation between Y151 and glycan N206, already leading to a partial shift of D150 and making it more prone to interact with glycan N206 (Fig. 6C). In D-TconTS1, instead, D150 was far less mobile (Fig. 6C).

Two important residues in TcruTS (Y119, W312) have been shown to serve as a holder for lactose once a substrate is bound in the active site and can be present in an open or stacked conformation $(45,46)$. Consistently with the results reported by Mitchell et al. (46), the corresponding residues Y211 and Y408 in TconTS1 (Fig. 6 A/B, orange circles) showed a high flexibility and presented an open conformation with an average distance of $2.2 \mathrm{~nm}$ in the absence of a substrate (Fig. 7). For comparison, these two residues stayed in much closer contact in D-TconTS1, remaining at a distance of about $1.6 \mathrm{~nm}$ during our simulation (Fig. 7A).

\subsection{Dynamics of conserved amino acids in TconTS1-CD in the presence of substrate}

Further MD simulations of TconTS1 and D-TconTS1 were performed in complex with the substrate 3'SL. 3'SL was positioned in the binding site of TconTS1 in alignment with the crystal structure of the TcruTS/3'SL complex (PDB entry 1SOI). In the starting structure, 3'SL is bound at the acceptor substrate binding site between Y211 and Y408, and in close contact to both D150 and the well-conserved arginines R339, R410 (see Fig. 8A/B for TconTS1).

As already seen in the substrate-free simulation, D150 of TconTS1 formed hydrogen bonds with mannose residues of an $\mathrm{N}$-glycan. However, in this case it was glycan $\mathrm{N} 113$, which is also structurally in close proximity to the active site, and not glycan N206 (Fig. 8D). This interaction occured after 20 ns, when D150 moved slightly off the catalytic site and becoming more accessible for the $\mathrm{N}$-glycan (Fig. $8 \mathrm{C}$ ). After a 
structural rearrangement of 3'SL within the binding site after around 70 ns, D150 again interacted with glycan $\mathrm{N} 113$ and was dragged out of the binding site (Fig. 8C). In striking contrast, catalytic amino acids in D-TconTS1 did not experience any interactions with GlcNAc residues, which remained on the protein surface after EndoH $\mathrm{H}_{\mathrm{f}}$ treatment.

In the presence of a substrate, the behavior of Y211 and Y408 was reversed with respect to the substrate-free protein. Namely, the distance between the two amino acids was about $2 \mathrm{~nm}$ in TconTS1 but increased to more than $3 \mathrm{~nm}$ in D-TconTS1 (Fig. 7B).

\section{Discussion}

In this study, we have focused on the influence of $N$-glycosylation on enzyme activity and stability of TconTS1 from the animal pathogen $T$. congolense. Recombinant TconTS1 was expressed in the $N$-glycosylation mutant CHO Lec1 $(32,40)$. The cell line mainly yields $\mathrm{Man}_{5} \mathrm{GlcNAc}_{2} \mathrm{~N}$-glycans as these glycans cannot be further processed to complex glycans in the Golgi apparatus due to a lack of $\mathrm{N}$ acetylglucosaminyltransferase I (GlcNAc-TI) activity $(41,47)$.

By means of MALDI-TOF MS analyses we were able to show that at least seven out of nine potential $\mathrm{N}$-glycosylation sites in TconTS1 carry high-mannose type $\mathrm{N}$-glycans, five of which are located in the CD. A glycan heterogeneity was observed at the three potential $\mathrm{N}$-glycosylation site (N113, N206, N693) as also higher mannose structures $\left(\mathrm{Man}_{6} \mathrm{GlcNAc}_{2}\right.$, Man ${ }_{8} \mathrm{GlcNAc}_{2}$ ) and fucosylated glycans (Man $\mathrm{GlcNAc}_{2} \mathrm{Fuc}$ ) were detected in some MS spectra. This heterogeneity might be explained by the lack of accessibility of the glycan for glycosidases, since $N$-glycan precursors are trimmed from Man ${ }_{8} \mathrm{GlcNAc}_{2}$ to Man ${ }_{5} \mathrm{GlcNAc}_{2}$ in the Golgi (48). This hypothesis is supported by the fact that the glycosidase $\mathrm{EndoH}_{\mathrm{f}}$ was not able to fully deglycosylate TconTS1 at these sites even after $16 \mathrm{~h}$ of incubation. Additionally, our MD simulations revealed protein-glycan interactions at sites $\mathrm{N} 113$ and N206 by hydrogen bonds. It was previously shown by biochemical in vitro assays and computational studies that such interactions decrease glycan accessibility, which might hinder deglycosylation by EndoH $_{f}(49)$.

The secondary structure of TconTS1 was not influenced by the presence of highmannose type $\mathrm{N}$-glycans. First, circular dichroism spectra of deglycosylated and glycosylated proteins did not reveal differences in secondary structure elements. Second, a similar midpoint of unfolding transition was determined for both enzymes in temperature-ramping experiments, suggesting no difference in stability. Similar results were found in single-site $\mathrm{N}$-glycosylation mutants of the IBV spike protein by circular dichroism experiments (5). The observed thermal stability of TconTS1 might be explained by the high $ß$-sheet content of the protein as well as by an extended interface between CD and LD stabilized by salt bridges and a well-structured hydrogen bond network, making unfolding rather unlikely (35). Although $N$-glycans do not seem to influence the stability of TconTS1 after successful expression, glycans are known to be required for proper protein folding (3). Whether or not TconTS1 requires $N$ glycosylation for accurate protein folding cannot be excluded by our experiments, and the role of $\mathrm{N}$-glycans in TconTS folding still needs to be investigated. 
A prominent influence of $N$-glycosylation, however, was observed in enzyme activity assays. Lactose affinity of D-TconTS1 was decreased by a factor of five compared to TconTS1. However, the $V_{\max }$ value was the same for both enzymes, which corroborates the structural integrity of D-TconTS1. Haynes et al. (21) studied the influence of $\mathrm{N}$-glycosylation on TvivTS1 and did not observe an effect on enzyme activity. The same applies to investigations of a mutated variant of TranSA, which expresses transfer activity (22). However, these studies did not determine the $\mathrm{K}_{\mathrm{M}}$ values of the enzyme reaction. Another study of TranSA in which the sialidase activity was investigated, did not observe strong effects on $\mathrm{K}_{\mathrm{M}}$ when recombinant proteins were expressed in Escherichia (E.) coli were compared with the native enzymes isolated from trypanosomes (39). For TcruTS, enzymes expressed in E. coli still showed transfer activity although to a lesser extent than observed for the native protein, which might be explained by the absence of $\mathrm{N}$-glycans or incorrect protein folding (37).

Molecular insight into the effect of $N$-glycosylation of TconTS1 at the atomic level were obtained in a series of MD simulations. The $N$-glycans, especially in TconTS1-CD, were observed to form a highly dynamical 'shield' enclosing the enzyme, while leaving the entrance to the catalytic center open for substrate binding. Moreover, the simulations suggest a large structural flexibility of the aspartate at position 150 , which acts as a proton donor in the enzymatic transfer of Sia, and is therefore crucial for substrate conversion $(17,44)$.

In several simulations of TconTS1, both in the absence and presence of bound 3'SL, D150 forms either intermittent or stable hydrogen-bond interactions with $N$-glycans at positions N206 or N113. Interestingly, these are conserved N-glycosylation sites among TS or SA from different species, despite the dissimilar amino acid sequences and distributions of other $\mathrm{N}$-glycosylation sites. In particular, N206 is conserved in all TS variants of $T$. congolense as already described by Waespy et al. (25) but also in enzymes from $T$. cruzi , $T$. rangeli, $T$. brucei and $T$. vivax as revealed by sequence alignment (Fig. S5). Additionally, N113 is also conserved in TconTS, TvivTS and TranSA. Along this line, we propose that there might be a common mechanism of TS activity mediated by $N$-glycan interactions with amino acids of the active site, in particular with D150. MD simulations showed that through this interaction, which can only take place in glycosylated TconTS1, D150 was pulled out of the active site. Moreover, in 3'SL-free TconTS1 the distance between the ligand-binding residues Y211 and Y408 was significantly larger than that found in D-TconTS1. Both these observations suggest a more open structure of the catalytic pocket of TconTS1 in contrast to D-TconTS1, which facilitates the initial binding of sialoglycans.

Interaction of the $N$-glycan shield at position N113 with D150 was also observed in MD simulations of TconTS1 in complex with 3'SL, although more intermittent. Interestingly, the substrate was tightly bound between Y211 and Y408 in TconTS1, but not in DTconTS1. These findings provide good evidence for higher substrate-binding affinity in case of the glycosylated enzyme and are in line with our experimental observations.

We note that the heterogeneity of $\mathrm{N}$-glycosylation at $\mathrm{N} 206$, as determined experimentally in this study, was not considered in our MD simulations, so that the influence of different $\mathrm{N}$-glycan structures at this position on the catalytic activity remains a task for future works. However, our results underline the obvious importance of the flexibility of the $N$-glycan shield in its interaction with key amino acid residues 
located in the CD, which remained unnoticed in previous studies. The short time scale and lack of $\mathrm{N}$-glycans in previously performed MD simulations probably prevented the exploration of the D150 structural shift $(45,46,50,51)$. Mechanisms underlying the $N$ glycan-dependent modulation of enzymatic activity remain to be explored by advanced techniques enabling prediction of binding free energies and including hybrid quantum mechanics/molecular mechanics approaches, which have been beyond the scope of this study.

Our data further underline the general importance of MD simulations, since differences in the dynamical behavior of catalytic amino acids are not always detectable in wet-lab experiments. In particular, the D150 shift could not be detected in our circular dichroism experiments, because D150 is part of a turn/coil structural motif, which does not change its secondary structural composition irrespective of the location of D150 (Fig. S4).

In conclusion, our study demonstrates that $N$-glycosylation can enhance substrate affinity in TS, putatively via interactions of $\mathrm{N}$-glycans with amino acids located in the catalytic pocket. To the best of our knowledge this is the first time that interaction of the $N$-glycan shield with the underlying protein have been suggested to alter enzyme kinetics of TS. As $\mathrm{N}$-glycosylation sites are partially conserved among the transsialidase enzyme family, the here-observed protein-glycan interactions may also occur in TS of other trypanosomal species. This newly discovered regulatory feature opens up new avenues in TS and enzyme research in general and may pave the way for novel approaches to treat trypanosomiasis.

\section{Experimental procedures}

Chemicals and reagents used in this study were of cell-culture and analytical grade and were purchased from Sigma-Aldrich/Merck KGaA (Darmstadt, Germany) or Carl Roth (Karlsruhe, Germany) if not stated otherwise.

\section{Expression of TconTS1 in CHO Lec1 cells}

Recombinant TconTS1 was produced in CHO Lec1 cells as already described (32). In brief, a modified pDEF vector was used for stable transfection comprising a transin sequence for protein secretion followed by the TconTS1-encoding sequence excluding signal peptide and GPI anchor sequence, a C3 cleavage site and a C-terminal SNAP and Strep-tag. Monoclonal cells were grown in serum-free $\mathrm{CHO}$ medium (Bio\&SELL, Feucht, Germany) or Excell medium supplemented with $50 \mu \mathrm{g} / \mathrm{mL}$ gentamicin sulphate (Lonza ${ }^{\mathrm{TM}}$ BioWhittaker ${ }^{\mathrm{TM}}$, Walkersville, MD, USA) at $37^{\circ} \mathrm{C}$ and $5 \% \mathrm{CO}_{2}$.

\section{Purification of TconTS1 from cell culture supernatant}

Cell culture supernatant comprising the recombinant protein was harvested every second day and stabilized with $10 \mathrm{mM}$ Tris/HCl pH 8.0, $10 \mathrm{mM}$ EDTA, $10 \mathrm{mM}$ ascorbic acid and $0.02 \%$ sodium azide. Ultracentrifugation was performed at 7,800 rcf for 15 min followed by $40,000 \mathrm{rcf}$ for $45 \mathrm{~min}$ at $4^{\circ} \mathrm{C}$. The clear supernatant was microfiltered $(0.22 \mu \mathrm{m}, \mathrm{PES})$ and concentrated to $50 \mathrm{~mL}$ using a Sartorius ${ }^{\mathrm{TM}}$ Vivacell $^{\mathrm{TM}} 250$ PES Centrifugal Concentrator (Sartorius, Göttingen, Germany) with a MWCO of $100 \mathrm{kDa}$ and a pressure of 4 bar. Buffer was exchanged five times with $200 \mathrm{~mL}$ of $100 \mathrm{mM}$ Tris/ $\mathrm{HCl} \mathrm{pH} \mathrm{8.0,150} \mathrm{mM} \mathrm{NaCl,} 1 \mathrm{mM}$ EDTA and concentrated to a final volume of 
$10 \mathrm{~mL}$. The concentrate was centrifuged at 21,000 rcf for $30 \mathrm{~min}$ and recombinant protein was purified from the supernatant with Strep-Tactin ${ }^{\circledR}$ sepharose (IBA, Göttingen, Germany) according to the manufacturer's protocol. Elution fractions containing TconTS1 were pooled and buffer was exchanged four times with $5 \mathrm{~mL}$ of $10 \mathrm{mM}$ potassium phosphate buffer pH 7.4 using a Vivaspin ${ }^{\circ} 6$ Centrifugal Concentrator (Sartorius) at 2,000 rcf and $4^{\circ} \mathrm{C}$ for $20 \mathrm{~min}$. Protein samples were stored at $4^{\circ} \mathrm{C}$. TconTS1 concentrations were determined with a Pierce ${ }^{\mathrm{TM}}$ BCA Protein-Assay kit (Thermo Fisher Scientific, Schwerte, Germany) using BSA as standard.

\section{Deglycosylation of TconTS1}

$2 \mathrm{mg}$ of TconTS1 were deglycosylated with 40,000 Units EndoH $\mathrm{H}_{\mathrm{f}}(\mathrm{New}$ England Biolabs, Frankfurt am Main, Germany) for $16 \mathrm{~h}$ at $37^{\circ} \mathrm{C}$ in $2.0 \mathrm{~mL} 10 \mathrm{mM}$ phosphate buffer $\mathrm{pH}$ 7.4. The deglycosylated enzyme is termed D-TconTS1. A TconTS1 control without $\mathrm{EndoH}_{\mathrm{f}}$ addition was performed in parallel (TconTS1). The deglycosylated sample was purified again with Strep-Tactin $®$ sepharose to remove free glycans and EndoH $_{f}$ and buffer was exchanged to $10 \mathrm{mM}$ phosphate buffer $\mathrm{pH} 7.4$ as already described.

\section{SDS-PAGE, western blot and ConA lectin blot analysis}

Protein samples were separated via SDS-PAGE and either stained with PageBlue ${ }^{\mathrm{TM}}$ Protein Staining Solution (Thermo Fisher Scientific) or used for western blot or ConA lectin blot analysis. For western blots, a polyclonal rabbit anti-Strep (IBA) and a polyclonal, peroxidase-conjugated donkey anti-rabbit antibody (Jackson ImmunoResearch, Cambridgeshire, United Kingdom) were used as primary and secondary antibody, respectively. For ConA lectin blots, high-mannose $N$-glycosylated proteins were detected employing ConA-biotin (Galab, Hamburg, Germany) and the VECTASTAIN® ABC-HRP Kit (Vector Laboratories, Burlingame, CA, United States).

\section{MALDI-TOF MS analysis of TconTS1 N-glycosylation sites}

In-solution digestion of glycosylated and deglycosylated TconTS1 was performed with trypsin and chymotrypsin (Promega, Walldorf, Germany) to analyze peptides with MALDI-TOF MS. Protein solutions with a final concentration of $0.1 \mathrm{mg} / \mathrm{mL}$ were prepared in $50 \mathrm{mM} \mathrm{NH}_{4} \mathrm{HCO}_{3}$ buffer $\mathrm{pH}$ 7.8. Cysteine bonds were reduced with 1.4 $\mathrm{mM}$ DTT for $30 \mathrm{~min}$ at $50^{\circ} \mathrm{C}$ and the protein was denatured for $10 \mathrm{~min}$ at $95^{\circ} \mathrm{C}$. After a short cooling step on ice, cysteine residues were alkylated with IAA at a final concentration of $3.2 \mathrm{mM}$ for $30 \mathrm{~min}$ at $37^{\circ} \mathrm{C}$ and protected from light. Protein samples were digested with trypsin or chymotrypsin overnight at $37^{\circ} \mathrm{C}$ at protein:protease ratios of 25-100:1. Two negative controls were prepared accordingly, either lacking the protein TconTS1 (N1) or the protease (N2).

Samples were spotted directly on the target (Bruker Daltonics, Bremen, Germany) or glycopeptides were further purified with ConA beads as described under "Glycopeptide purification of protease-digested TconTS1 with ConA beads". For spotting, $1 \mu \mathrm{L}$ protein solution was directly mixed with $1 \mu \mathrm{L}$ HCCA matrix solution (40 mM in $50 \%$ acetonitrile/0.1\% TFA) on the target. Samples were measured in the positive reflector mode using the MALDI-TOF autoflex ${ }^{\mathrm{TM}}$ speed (Bruker Daltonics) which was calibrated with the peptide calibration standard II (Bruker Daltonics). Detailed settings can be found in Table S2. The software Flex analysis 3.4 (Bruker Corporation, USA) was employed for data evaluation. Monoisotopic peaks were identified with Sophisticated 
Numerical Annotation Procedure (SNAP) algorithm a signal to noise ratio of 6 . Further settings included baseline subtraction (TopHat) and spectra smoothing (algorithm: Savitzky Golay). Peaks present in any control have been automatically excluded from sample mass lists.

\section{Glycopeptide purification of protease-digested TconTS1 with ConA beads}

To concentrate glycopeptides from protease-digested TconTS1, samples were incubated with AffiSep ${ }^{\circledR}$ ConA adsorbent (Galab). The adsorbent was equilibrated in 1x binding buffer (50 mM Tris/ $\mathrm{HCl} \mathrm{pH} \mathrm{7.4,} 150 \mathrm{mM} \mathrm{NaCl}, 1 \mathrm{mM} \mathrm{CaCl} 2,1 \mathrm{mM} \mathrm{MgCl}, 1$ $\mathrm{mM} \mathrm{MnCl} 2$ ) and was added to trypsin-digested and heat-inactivated protein samples in a ratio of $1 \mu \mathrm{L}$ adsorbent $/ 2.5 \mu \mathrm{g}$ protein). $5 \mathrm{x}$ binding buffer of appropriate volumes was supplied to samples to yield a final concentration of 1x. Samples were rotated overnight at $8 \mathrm{rpm}$ and $4^{\circ} \mathrm{C}$ and centrifuged for $30 \mathrm{~s}$ at $130 \mathrm{rcf}$. The supernatant was discarded, and the adsorbent was washed thrice with $50 \mathrm{mM} \mathrm{NH}_{4} \mathrm{HCO}_{3}$ buffer $(\mathrm{pH} 7.8)$ in binding buffer and at the same centrifugation conditions. After the last centrifugation step the adsorbent was resuspended in $10-50 \mu \mathrm{L}$ of $\mathrm{NH}_{4} \mathrm{HCO}_{3}$ buffer $(\mathrm{pH} 7.8)$. Elution of glycopeptides was performed at $95^{\circ} \mathrm{C}$ for $10 \mathrm{~min}$. Samples were centrifuged at 4,300 rcf for $30 \mathrm{~s}$. The supernatant was used for MALDI-TOF analysis. Negative controls were prepared in parallel with identical components apart from the trypsin-digested TconTS1. Peaks resulting from negative controls were excluded for data analysis.

\section{TS activity assay}

TS activity assays were executed as previously described $(32,36)$. Fetuin and lactose served as Sia donor and acceptor, respectively. Reactions were carried out in $50 \mu \mathrm{L}$ of $10 \mathrm{mM}$ potassium phosphate buffer, $\mathrm{pH} 7.4$ containing $100 \mu \mathrm{g}$ dialyzed fetuin (corresponding to $600 \mu \mathrm{M}$ bound Neu5Ac), varying concentrations of lactose (0.01-5 $\mathrm{mM}$ ) and $50 \mathrm{ng}$ deglycosylated TconTS1 or the corresponding control. Samples were incubated at $37^{\circ} \mathrm{C}$ for $30 \mathrm{~min}$ and the reaction was terminated with $200 \mu \mathrm{L}$ ice-cold acetone. After protein precipitation overnight at $-20^{\circ} \mathrm{C}$, samples were centrifuged (20000 rcf, $30 \mathrm{~min}, 4^{\circ} \mathrm{C}$ ), lyophilized and resuspended in $125 \mu \mathrm{L}$ water. Transfer activity was measured as 3'SL implementing the HPAEC-PAD system ICS-5000+ (Dionex/Thermo Fisher Scientific). $25 \mu \mathrm{L}$ sample were applied to a CarboPac100 analytical column $(250 \times 2 \mathrm{~mm}, 8.5 \mu \mathrm{m}$, Thermo Fisher Scientific) equipped with a guard column (50x2 mm, Thermo Fisher Scientific). Chromatography was performed at isocratic conditions with $100 \mathrm{mM} \mathrm{NaOH}$ and $100 \mathrm{mM} \mathrm{NaOAc}$ for 12 min followed by a wash step with $100 \mathrm{mM} \mathrm{NaOH}$ and $500 \mathrm{mM} \mathrm{NaOAc}$ for 5 min and an equilibration step for $8 \mathrm{~min}$ to previous conditions. Production of 3'SL was quantified with a purchased 3'SL standard (Carbosynth, Compton, United Kingdom). Data acquisition and evaluation was performed with the Dionex software Chromeleon 7.2 SR5. Parameters of the Michaelis-Menten equation, $\mathrm{K}_{\mathrm{M}}$ and $\mathrm{V}_{\max }$, were calculated with the curve fit model of SigmaPlot11.

\section{Circular dichroism experiments}

Circular dichroism experiments were performed with purified recombinant TconTS1 in its glycosylated and deglycosylated form dissolved in $10 \mathrm{mM}$ phosphate buffer $\mathrm{pH} 7.4$. The Applied Photophysics Chirascan spectrometer (Applied Photophysics Limited, Leatherhead, UK) with the Pro-Data Chirascan software (v.4.2.22) was used to record and evaluate circular dichroism spectra. For each sample, at least three repetitive 
scans were performed over a standard wavelength range of 190 to $250 \mathrm{~nm}$ with intervals of $1 \mathrm{~nm}$. Throughout the experiments, Suprasil quartz cells (Hellma UK Ltd.) were used with a pathlength of $0.2 \mathrm{~mm}$. Baseline scans were performed with $10 \mathrm{mM}$ phosphate buffer ( $\mathrm{pH} 7.4)$ only, in the respective cuvette. Regarding data processing, the baseline was subtracted from recorded spectra and repetitive scans were averaged before a Savitsky-Golay smoothing filter with smoothing windows of three data points was applied. Spectra have been recorded in raw ellipticity $(\Theta)$ and were further converted to mean residue ellipticity

$$
\Theta_{M R E}=\frac{\Theta}{\operatorname{cln}}
$$

, where $c$ is the protein concentration, $l$ the quartz cuvette pathlength and $n$ the number of amino acids in the protein sequence. To be consistent with the parameters of the enzyme assay, constant-temperature measurements were performed at $35^{\circ} \mathrm{C}$ to check for a general influence of glycans on the protein structure.

To estimate the secondary structure components of the measured sample, circular dichroism spectra were analyzed using the BeStSel Web server $(52,53)$. Temperatureramping experiments were performed following the suggestions of (54) in order to analyze protein stability, unfolding intermediates and the midpoint of the unfolding transition (melting temperature, $T_{M}$ ). In detail, protein samples were heated from $20^{\circ} \mathrm{C}$ up to $95^{\circ} \mathrm{C}$ with $5^{\circ} \mathrm{C}$ temperature steps employing the stepped ramp mode. After 5 min of equilibration time at the respective temperature at least three spectra were recorded and averaged. The $T_{M}$ was calculated from the fraction of protein folded at any temperature $(\alpha)$ defined as:

$$
\alpha=(\Theta T-\Theta U) /(\Theta F-\Theta U),
$$

where $\Theta T$ is the ellipticity at any temperature, $\Theta U$ is the ellipticity at the unfolded state and $\Theta F$ at the folded state. $\mathrm{T}_{\mathrm{M}}$ is defined as the temperature at which $\alpha=0.5$ [Greenfield 2006] and also referred to as the melting temperature. In order to calculate $\alpha$, we chose $195 \mathrm{~nm}$ as the wavelength to plot recorded $\Theta_{M R E}$ values against the temperature. Afterwards, the calculated $\alpha$ values were again plotted with reference to temperature and a sigmoid curve used for fitting to obtain a precise TM value. As we did not observe a complete unfolding of TconTS1 in any temperature-ramping experiment, $\Theta U$ is defined as the average ellipticity of the two highest temperatures. Therefore, $\Theta F$ was set as the average ellipticity that was recorded for the two lowest temperatures.

\section{Atomistic model of (de-)glycosylated TconTS1}

Structures of TS from $T$. congolense have not been resolved so far by experimental techniques. Therefore an atomistic structure of TconTS1 was modelled by the ITASSER web server for protein structure and function predictions $(55,56)$ based on the recombinant sequence without the transin signal (Fig. S1 - amino acids 23-951). However, the numbering of amino acids is in correspondence with the native sequence, as depicted in Figure S1B (32). As TconTS1 was modelled with the engineered SNAP-Strep for consistency and better comparison with experimental data, restraints were used to achieve proper folding of this structural part. In detail, a secondary structure restraint as well as a structure template for the SNAP-Strep region, constructed by I-TASSER beforehand using only the SNAP-Strep sequence, were employed. Major templates employed by the threading algorithm were TranSA 
(PDB entry: 2agsA, 2A75) as well as TcruTS (PDB entry: 1ms9). The first model with a C-score of -2.99 was further used in this study.

\section{Construction of the simulation cell}

The freely accessible CHARMM-GUI Glycan Modeler (www.charmm-gui.org) was employed to form a disulfide bond between residues C493 and C503. For TconTS1, Man $_{5} \mathrm{GlcNAc}_{2} \mathrm{~N}$-glycans were attached at positions N45, N113, N206, N240, N281 and N693 with CHARMM-GUI (57-62) as identified with MALDI-TOF MS. Man ${ }_{5} \mathrm{GlCNAC}_{2}$ was chosen for all sites, as it represents the simplest and most often found $\mathrm{N}$-glycan in CHO Lec1 cells (41). N657 was not glycosylated, although found in our MALDI experiments, because model building was already completed at the time this glycan was found. D-TconTS1 was constructed by the addition of one GIcNAc residue via a covalent linkage at positions N45, N113, N206, N240, N281 and N693. The simulation box was constructed with CHARMM-GUI, filling it with water molecules to obtain a distance of $15 \AA$ between the protein and box edge. $22 \mathrm{~K}^{+}$ions have been added for charge neutralization.

\section{Molecular dynamics simulation}

All MD simulations were performed with the GROMACS 2018 version (63), using the CHARMM36m (64) force field for proteins, $N$-glycans and 3'SL $(65,66)$ in combination with the TIP3P water model. The leap-frog algorithm was used as an integrator and the LINCS algorithm (67) was employed to constrain bonds connected to hydrogens atoms. Temperature coupling was performed with velocity rescaling using a $\tau$ parameter of $0.1 \mathrm{ps}(68)$. The verlet cut-off scheme (69) was employed for van der Waals parameters using PME and the standardized parameters suggested for CHARMM36 in the GROMACS manual version 2019.

Energy minimizations of water and ions (with restrained proteins) were performed using the steepest descent algorithm with a tolerance of $1,000 \mathrm{~kJ} \mathrm{~mol}^{-1} \mathrm{~nm}^{-1}$. Equilibration of water (with restrained proteins) was done in an NVT and an NPT ensemble for $1 \mathrm{~ns}$, respectively. It followed the energy minimization of the proteins (with restrained water and ions) under the same conditions as before. Finally, unrestrained equilibrations were performed under NVT and NPT for 1 ns each. The production runs were performed for $500 \mathrm{~ns}$ in the NVT ensemble at $310.15 \mathrm{~K}$, writing coordinates to file every $10 \mathrm{ps}$. A time step of $2 \mathrm{fs}$ was set for all parts of the simulations if not mentioned otherwise. The systems were analyzed and visualized every 500 ps using VMD (http://www.ks.uiuc.edu/Research/vmd/), the open-source communitydeveloped PLUMED library version 2.6 and Python version 3.7 (70-74).

\section{Construction of TconTS1 in complex with 3'SL}

3'SL was chosen as a substrate since its composition is similar to the typical terminal branches of complex type $\mathrm{N}$-glycans and was already used in previous enzyme assays (9). To ensure a correct binding pose of the ligand in the catalytic site, the homologymodelled TconTS1 structure was aligned to the pdb structure of TcruTS (pdb: 1s0i) in complex with 3'SL by VMD. The position of 3'SL was copied to the TconTS structure, and the ligand-protein complex was subjected to CHARMM-GUI for further processing, as described under section "Construction of the simulation cell". Further minimization and equilibration steps were performed as described under section "Molecular 
Dynamics simulation", using a timestep of 1 or 2 fs to resolve steric clashes. Production runs were performed as mentioned above.

\section{Data availability}

The underlying data of this study, such as raw spectra of MALDI-TOF MS and circular dichroism experiments as well as structure and trajectory files of MD simulations are made available under https://doi.org/10.5281/zenodo.5775026.

\section{Supporting information}

This article contains supporting information.

\section{Acknowledgements}

The authors would like to thank Dr. Jan-Hendrik Hehemann (MARUM MPG Bridge Group Marine Glycobiology, Bremen, Germany) for the possibility of performing the HPAEC-PAD measurements in his lab and Alek Bolte for the technical support. They further thank Monika Michaelis for her assistance with circular dichroism measurements and for fruitful discussions.

\section{Author contributions}

Conceived and designed the experiments: JR ILG LC SK MW. MALDI-TOF MS experiments: JR ILG YY, Enzyme assays: JR ILG YY, Circular dichroism: ILG YY, Molecular dynamics simulation: ILG. Data analysis: JR ILG. Manuscript writing: JR ILG. Manuscript revision: LC SK MW.

\section{Funding and additional information}

Computational resources were provided by the North German Supercomputing Alliance (HLRN) under the project number hbb00001. This study's financial support came from the Deutsche Forschungsgemeinschaft (DFG: https://www.dfg.de/), project grants to SK, Ke428/10-1 and Ke428/13-1). The funders had no role in study design, data collection and analysis, decision to publish, or preparation of the manuscript.

\section{Conflict of interest}

The authors declare that they have no conflicts of interest with the contents of this article.

\section{References}


bioRxiv preprint doi: https://doi.org/10.1101/2021.12.13.472379; this version posted December 14, 2021. The copyright holder for this

1. Skropeta, D. (2009) The effect of individual $\mathrm{N}$-glycans on enzyme activity. Bioorg Med Chem. 17, 2645-2653

2. Varki, A. (1993) Biological roles of oligosaccharides: all of the theories are correct. Glycobiology. 3, 97-130

3. Varki, A., Cummings, R. D., Esko, J. D., Stanley, P., Hart, G. W., Aebi, M., Darvill, A. G., Kinoshita, T., Packer, N. H., Prestegard, J. H., Schnaar, R. L., and Seeberger, P. H. (eds.) (2015) Essentials of glycobiology, 3rd Ed., Cold Spring Harbor Laboratory Press, Cold Spring Harbor (NY), [online] http://www.ncbi.nlm.nih.gov/books/NBK310274/ (Accessed March 11, 2021)

4. Casalino, L., Gaieb, Z., Goldsmith, J. A., Hjorth, C. K., Dommer, A. C., Harbison, A. M., Fogarty, C. A., Barros, E. P., Taylor, B. C., McLellan, J. S., Fadda, E., and Amaro, R. E. (2020) Beyond shielding: The roles of glycans in the SARS-CoV-2 spike protein. ACS Cent Sci. 6, 1722-1734

5. Parsons, L. M., Bouwman, K. M., Azurmendi, H., de Vries, R. P., Cipollo, J. F., and Verheije, M. H. (2019) Glycosylation of the viral attachment protein of avian coronavirus is essential for host cell and receptor binding. J Biol Chem. 294, 7797-7809

6. Wasim, L., Buhari, F. H. M., Yoganathan, M., Sicard, T., Ereño-Orbea, J., Julien, J.-P., and Treanor, B. (2019) N-Linked glycosylation regulates CD22 organization and function. Front Immunol. 10, 699

7. Schenkman, S., Jiang, M. S., Hart, G. W., and Nussenzweig, V. (1991) A novel cell surface transsialidase of Trypanosoma cruzi generates a stage-specific epitope required for invasion of mammalian cells. Cell. 65, 1117-1125

8. Engstler, M., Reuter, G., and Schauer, R. (1993) The developmentally regulated trans-sialidase from Trypanosoma brucei sialylates the procyclic acidic repetitive protein. Mol Biochem Parasitol. 61, 1-13

9. Engstler, M., Schauer, R., and Brun, R. (1995) Distribution of developmentally regulated transsialidases in the Kinetoplastida and characterization of a shed trans-sialidase activity from procyclic Trypanosoma congolense. Acta Trop. 59, 117-129

10. Guegan, F., Plazolles, N., Baltz, T., and Coustou, V. (2013) Erythrophagocytosis of desialylated red blood cells is responsible for anaemia during Trypanosoma vivax infection: Erythrophagocytosis during T. vivax infection. Cell Microbiol. 15, 1285-1303

11. Pontes de Carvalho, L. C., Tomlinson, S., Vandekerckhove, F., Bienen, E. J., Clarkson, A. B., Jiang, M. S., Hart, G. W., and Nussenzweig, V. (1993) Characterization of a novel trans-sialidase of Trypanosoma brucei procyclic trypomastigotes and identification of procyclin as the main sialic acid acceptor. J Exp Med. 177, 465-474

12. Ming, M., Chuenkova, M., Ortega-Barria, E., and Pereira, M. E. A. (1993) Mediation of Trypanosoma cruzi invasion by sialic acid on the host cell and trans-sialidase on the trypanosome. Mol Biochem Parasitol. 59, 243-252

13. Schenkman, S., Ferguson, M. A. J., Heise, N., Cardoso de Almeida, M. L., Mortara, R. A., and Yoshida, N. (1993) Mucin-like glycoproteins linked to the membrane by glycosylphosphatidylinositol anchor are the major acceptors of sialic acid in a reaction catalyzed by trans-sialidase in metacyclic forms of Trypanosoma cruzi. Mol Biochem Parasitol. 59, 293-303

14. Tomlinson, S., Pontes de Carvalho, L. C., Vandekerckhove, F., and Nussenzweig, V. (1994) Role of sialic acid in the resistance of Trypanosoma cruzi trypomastigotes to complement. Journal of Immunology. 153, 3141-7

15. Pereira-Chioccola, V. L., Acosta-Serrano, A., Correia de Almeida, I., Ferguson, M. A., SoutoPadron, T., Rodrigues, M. M., Travassos, L. R., and Schenkman, S. (2000) Mucin-like molecules form a negatively charged coat that protects Trypanosoma cruzi trypomastigotes from killing by human anti-a-galactosyl antibodies. J Cell Sci. 113 ( Pt 7), 1299-1307

16. Nagamune, K., Acosta-Serrano, A., Uemura, H., Brun, R., Kunz-Renggli, C., Maeda, Y., Ferguson, M. A. J., and Kinoshita, T. (2004) Surface sialic acids taken from the host allow trypanosome survival in tsetse fly vectors. J Exp Med. 199, 1445-1450

17. Buschiazzo, A. (2000) Structural basis of sialyltransferase activity in trypanosomal sialidases. The EMBO Journal. 19, 16-24

18. Buschiazzo, A., Amaya, M. F., Cremona, M. L., Frasch, A. C., and Alzari, P. M. (2002) The crystal structure and mode of action of trans-sialidase, a key enzyme in Trypanosoma cruzi pathogenesis. Mol Cell. 10, 757-768

19. Amaya, M. F., Watts, A. G., Damager, I., Wehenkel, A., Nguyen, T., Buschiazzo, A., Paris, G., Frasch, A. C., Withers, S. G., and Alzari, P. M. (2004) Structural insights into the catalytic mechanism of Trypanosoma cruzi trans-sialidase. Structure. 12, 775-784

20. Pierdominici-Sottile, G., Horenstein, N. A., and Roitberg, A. E. (2011) Free energy study of the catalytic mechanism of Trypanosoma cruzi trans -sialidase. From the Michaelis complex to the covalent intermediate. Biochemistry. 50, 10150-10158 
bioRxiv preprint doi: https://doi.org/10.1101/2021.12.13.472379; this version posted December 14, 2021. The copyright holder for this preprint (which was not certified by peer review) is the author/funder, who has granted bioRxiv a license to display the preprint in perpetuity. It is made available under aCC-BY 4.0 International license.

21. Haynes, C. L. F., Ameloot, P., Remaut, H., Callewaert, N., Sterckx, Y. G.-J., and Magez, S. (2015) Production, purification and crystallization of a trans -sialidase from Trypanosoma vivax. Acta Crystallogr F Struct Biol Commun. 71, 577-585

22. Li, H., Rasmussen, M. I., Larsen, M. R., Guo, Y., Jers, C., Palmisano, G., Mikkelsen, J. D., and Kirpekar, F. (2015) Automated $N$-glycan profiling of a mutant Trypanosoma rangeli sialidase expressed in Pichia pastoris, using tandem mass spectrometry and bioinformatics. Glycobiology. 25, 1350-1361

23. Schenkman, S., Pontes de Carvalho, L., and Nussenzweig, V. (1992) Trypanosoma cruzi transsialidase and neuraminidase activities can be mediated by the same enzymes. J Exp Med. 175, $567-575$

24. Engstler, M., Reuter, G., and Schauer, R. (1992) Purification and characterization of a novel sialidase found in procyclic culture forms of Trypanosoma brucei. Mol Biochem Parasitol. 54, $21-$ 30

25. Waespy, M., Gbem, T. T., Elenschneider, L., Jeck, A.-P., Day, C. J., Hartley-Tassell, L., Bovin, N., Tiralongo, J., Haselhorst, T., and Kelm, S. (2015) Carbohydrate recognition specificity of transsialidase lectin domain from Trypanosoma congolense. PLOS Neglected Tropical Diseases

26. Savage, A., Geyer, R., Stirm, S., Reinwald, E., and Risse, H. J. (1984) Structural studies on the major oligosaccharides in a variant surface glycoprotein of Trypanosoma congolense. Mol Biochem Parasitol. 11, 309-328

27. Zamze, S. E., Wooten, E. W., Ashford, D. A., Ferguson, M. A. J., Dwek, R. A., and Rademacher, T. W. (1990) Characterisation of the asparagine-linked oligosaccharides from Trypanosoma brucei type-I variant surface glycoproteins. Eur J Biochem. 187, 657-663

28. Zamze, S. E., Ashford, D. A., Wooten, E. W., Rademacher, T. W., and Dwek, R. A. (1991) Structural characterization of the asparagine-linked oligosaccharides from Trypanosoma brucei type II and type III variant surface glycoproteins. J Biol Chem. 266, 20244-20261

29. Treumann, A., Zitzmann, N., Hülsmeier, A., Prescott, A., Sheehan, J., and Ferguson, M. A. J. (1997) Structural characterisation of two forms of procyclic acidic repetitive protein expressed by procyclic forms of Trypanosoma brucei. J Mol Biol. 269, 529-547

30. Mehlert, A., Zitzmann, N., Richardson, J. M., Treumann, A., and Ferguson, M. A. J. (1998) The glycosylation of the variant surface glycoproteins and procyclic acidic repetitive proteins of Trypanosoma brucei. Mol Biochem Parasitol. 91, 145-152

31. Utz, S., Roditi, I., Kunz Renggli, C., Almeida, I. C., Acosta-Serrano, A., and Bütikofer, P. (2006) Trypanosoma congolense procyclins: unmasking cryptic major surface glycoproteins in procyclic forms. Eukaryot Cell. 5, 1430-1440

32. Koliwer-Brandl, H., Gbem, T. T., Waespy, M., Reichert, O., Mandel, P., Drebitz, E., Dietz, F., and Kelm, S. (2011) Biochemical characterization of trans-sialidase TS1 variants from Trypanosoma congolense. BMC Biochem. 12, 39

33. Coustou, V., Plazolles, N., Guegan, F., and Baltz, T. (2012) Sialidases play a key role in infection and anaemia in Trypanosoma congolense animal trypanosomiasis. Cell Microbiol. 14, 431-445

34. Nok, A. J., and Balogun, E. O. (2003) A bloodstream Trypanosoma congolense sialidase could be involved in anemia during experimental trypanosomiasis. J Biochem. 133, 725-730

35. [preprint] Waespy, M., Gbem, T. T., Kumar, N. D., Mani, S. S., Rosenau, J., Dietz, F., and Kelm, S. (2021) Cooperativity of catalytic and lectin-like domain of $T$. congolense trans-sialidase modulates its catalytic activity. bioRxiv. 10.1101/2021.05.28.446113

36. Gbem, T. T., Waespy, M., Hesse, B., Dietz, F., Smith, J., Chechet, G. D., Nok, J. A., and Kelm, S. (2013) Biochemical diversity in the Trypanosoma congolense trans-sialidase family. PLoS Negl Trop Dis. 7, e2549

37. Campetella, O. E., Uttaro, A. D., Parodi, A. J., and Frasch, A. C. C. (1994) A recombinant Trypanosoma cruzi trans-sialidase lacking the amino acid repeats retains the enzymatic activity. Mol Biochem Parasitol. 64, 337-340

38. Montagna, G. N., Donelson, J. E., and Frasch, A. C. C. (2006) Procyclic Trypanosoma brucei expresses separate sialidase and trans-sialidase enzymes on its surface membrane. J Biol Chem. 281, 33949-33958

39. Buschiazzo, A., Campetella, O., and Frasch, A. C. C. (1997) Trypanosoma rangeli sialidase: cloning, expression and similarity to T.cruzi trans-sialidase. Glycobiology. 7, 1167-1173

40. Stanley, P. (1984) Glycosylation mutants of animal cells. Annu Rev Genet. 18, 525-552

41. North, S. J., Huang, H.-H., Sundaram, S., Jang-Lee, J., Etienne, A. T., Trollope, A., Chalabi, S., Dell, A., Stanley, P., and Haslam, S. M. (2010) Glycomics profiling of chinese hamster ovary cell glycosylation mutants reveals $\mathrm{N}$-glycans of a novel size and complexity. J Biol Chem. 285, 57595775 
42. Nishikaze, T. (2017) Sensitive and structure-informative N-glycosylation analysis by MALDI-MS; Ionization, fragmentation, and derivatization. Mass Spectrom (Tokyo). 6, A0060-A0060

43. Sheng, L., He, Z., Chen, J., Liu, Y., Ma, M., and Cai, Z. (2017) The impact of N-glycosylation on conformation and stability of immunoglobulin $Y$ from egg yolk. Int J Biol Macromol. 96, 129-136

44. Tiralongo, E., Martensen, I., Grötzinger, J., Tiralongo, J., and Schauer, R. (2003) Trans-sialidaselike sequences from Trypanosoma congolense conserve most of the critical active site residues found in other trans-sialidases. Biol Chem. 384, 1203-1213

45. Demir, Ö., and Roitberg, A. E. (2009) Modulation of catalytic function by differential plasticity of the active site: case study of Trypanosoma cruzi trans-sialidase and Trypanosoma rangeli sialidase. Biochemistry. 48, 3398-3406

46. Mitchell, F. L., Miles, S. M., Neres, J., Bichenkova, E. V., and Bryce, R. A. (2010) Tryptophan as a molecular shovel in the glycosyl transfer activity of Trypanosoma cruzi trans-sialidase. Biophys $J$. 98, L38-L40

47. Chen, W., and Stanley, P. (2003) Five Lec1 CHO cell mutants have distinct Mgat1 gene mutations that encode truncated $N$-acetylglucosaminyltransferase I. Glycobiology. 13, 43-50

48. Stanley, P., Taniguchi, N., and Aebi, M. (2015) N-glycans. in Essentials of Glycobiology, 3rd Ed. (Varki, A., Cummings, R. D., Esko, J. D., Stanley, P., Hart, G. W., Aebi, M., Darvill, A. G., Kinoshita, T., Packer, N. H., Prestegard, J. H., Schnaar, R. L., and Seeberger, P. H. eds), Cold Spring Harbor Laboratory Press, Cold Spring Harbor (NY), [online] http://www.ncbi.nlm.nih.gov/books/NBK453020/ (Accessed March 7, 2021)

49. Mathew, C., Weiß, R. G., Giese, C., Lin, C.-W., Losfeld, M.-E., Glockshuber, R., Riniker, S., and Aebi, M. (2021) Glycan-protein interactions determine kinetics of $\mathrm{N}$-glycan remodeling. RSC Chem Biol. 2, 917-931

50. Mitchell, F. L., Neres, J., Ramraj, A., Raju, R. K., Hillier, I. H., Vincent, M. A., and Bryce, R. A. (2013) Insights into the activity and specificity of Trypanosoma cruzi trans -sialidase from molecular dynamics simulations. Biochemistry. 52, 3740-3751

51. Oliveira, I. A., Gonçalves, A. S., Neves, J. L., von Itzstein, M., and Todeschini, A. R. (2014) Evidence of ternary complex formation in Trypanosoma cruzi trans-sialidase catalysis. J Biol Chem. 289, 423-436

52. Micsonai, A., Wien, F., Kernya, L., Lee, Y.-H., Goto, Y., Réfrégiers, M., and Kardos, J. (2015) Accurate secondary structure prediction and fold recognition for circular dichroism spectroscopy. PNAS. 112, E3095-E3103

53. Micsonai, A., Wien, F., Bulyáki, É., Kun, J., Moussong, É., Lee, Y.-H., Goto, Y., Réfrégiers, M., and Kardos, J. (2018) BeStSel: a web server for accurate protein secondary structure prediction and fold recognition from the circular dichroism spectra. Nucleic Acids Res. 46, W315-W322

54. Greenfield, N. J. (2006) Using circular dichroism collected as a function of temperature to determine the thermodynamics of protein unfolding and binding interactions. Nat Protoc. 1, 25272535

55. Roy, A., Kucukural, A., and Zhang, Y. (2010) I-TASSER: a unified platform for automated protein structure and function prediction. Nat Protoc. 5, 725-738

56. Yang, J., and Zhang, Y. (2015) I-TASSER server: new development for protein structure and function predictions. Nucleic Acids Res. 43, W174-W181

57. Brooks, B. R., Brooks, C. L., MacKerell, A. D., Nilsson, L., Petrella, R. J., Roux, B., Won, Y., Archontis, G., Bartels, C., Boresch, S., Caflisch, A., Caves, L., Cui, Q., Dinner, A. R., Feig, M., Fischer, S., Gao, J., Hodoscek, M., Im, W., Kuczera, K., Lazaridis, T., Ma, J., Ovchinnikov, V., Paci, E., Pastor, R. W., Post, C. B., Pu, J. Z., Schaefer, M., Tidor, B., Venable, R. M., Woodcock, H. L., Wu, X., Yang, W., York, D. M., and Karplus, M. (2009) CHARMM: The biomolecular simulation program. J Comput Chem. 30, 1545-1614

58. Jo, S., Kim, T., Iyer, V. G., and Im, W. (2008) CHARMM-GUI: a web-based graphical user interface for CHARMM. J Comput Chem. 29, 1859-1865

59. Jo, S., Song, K. C., Desaire, H., MacKerell, A. D., and Im, W. (2011) Glycan Reader: automated sugar identification and simulation preparation for carbohydrates and glycoproteins. $J$ Comput Chem. 32, 3135-3141

60. Lee, J., Cheng, X., Swails, J. M., Yeom, M. S., Eastman, P. K., Lemkul, J. A., Wei, S., Buckner, J., Jeong, J. C., Qi, Y., Jo, S., Pande, V. S., Case, D. A., Brooks, C. L., MacKerell, A. D., Klauda, J. B., and Im, W. (2016) CHARMM-GUI input generator for NAMD, GROMACS, AMBER, OpenMM, and CHARMM/OpenMM simulations using the CHARMM36 additive force field. $J$ Chem Theory Comput. 12, 405-413

61. Park, S.-J., Lee, J., Patel, D. S., Ma, H., Lee, H. S., Jo, S., and Im, W. (2017) Glycan Reader is improved to recognize most sugar types and chemical modifications in the Protein Data Bank. Bioinformatics. 33, 3051-3057 
62. Park, S.-J., Lee, J., Qi, Y., Kern, N. R., Lee, H. S., Jo, S., Joung, I., Joo, K., Lee, J., and Im, W. (2019) CHARMM-GUI Glycan Modeler for modeling and simulation of carbohydrates and glycoconjugates. Glycobiology. 29, 320-331

63. Abraham, M. J., Murtola, T., Schulz, R., Páll, S., Smith, J. C., Hess, B., and Lindahl, E. (2015) GROMACS: High performance molecular simulations through multi-level parallelism from laptops to supercomputers. SoftwareX. 1-2, 19-25

64. Huang, J., Rauscher, S., Nawrocki, G., Ran, T., Feig, M., de Groot, B. L., Grubmüller, H., and MacKerell, A. D. (2017) CHARMM36m: an improved force field for folded and intrinsically disordered proteins. Nat Methods. 14, 71-73

65. Guvench, O., Hatcher, E., Venable, R. M., Pastor, R. W., and MacKerell, A. D. (2009) CHARMM additive all-atom force field for glycosidic linkages between hexopyranoses. $J$ Chem Theory Comput. 5, 2353-2370

66. Guvench, O., Mallajosyula, S. S., Raman, E. P., Hatcher, E., Vanommeslaeghe, K., Foster, T. J., Jamison, F. W., and Mackerell, A. D. (2011) CHARMM additive all-atom force field for carbohydrate derivatives and its utility in polysaccharide and carbohydrate-protein modeling. $J$ Chem Theory Comput. 7, 3162-3180

67. Hess, B., Bekker, H., Berendsen, H. J. C., and Fraaije, J. G. E. M. (1997) LINCS: A linear constraint solver for molecular simulations. J Comput Chem. 18, 1463-1472

68. Bussi, G., Donadio, D., and Parrinello, M. (2007) Canonical sampling through velocity rescaling. J Chem Phys. 126, 014101

69. Páll, S., and Hess, B. (2013) A flexible algorithm for calculating pair interactions on SIMD architectures. Comput Phys Commun. 184, 2641-2650

70. Bonomi, M., Branduardi, D., Bussi, G., Camilloni, C., Provasi, D., Raiteri, P., Donadio, D., Marinelli, F., Pietrucci, F., Broglia, R. A., and Parrinello, M. (2009) PLUMED: a portable plugin for free-energy calculations with molecular dynamics. Comput Phys Commun. 180, 1961-1972

71. The PLUMED consortium (2019) Promoting transparency and reproducibility in enhanced molecular simulations. Nat Methods. 16, 670-673

72. Tribello, G. A., Bonomi, M., Branduardi, D., Camilloni, C., and Bussi, G. (2014) PLUMED 2: New feathers for an old bird. Comput Phys Commun. 185, 604-613

73. Humphrey, W., Dalke, A., and Schulten, K. (1996) VMD: visual molecular dynamics. J Mol Graph. 14, 33-38, 27-28

74. Stone, J. (1998) An Efficient Library for Parallel Ray Tracing and Animation. Ph.D. thesis, University of Missouri-Rolla, Computer Science Department

75. Varki, A., Cummings, R. D., Aebi, M., Packer, N. H., Seeberger, P. H., Esko, J. D., Stanley, P., Hart, G., Darvill, A., Kinoshita, T., Prestegard, J. J., Schnaar, R. L., Freeze, H. H., Marth, J. D., Bertozzi, C. R., Etzler, M. E., Frank, M., Vliegenthart, J. F., Lütteke, T., Perez, S., Bolton, E., Rudd, P., Paulson, J., Kanehisa, M., Toukach, P., Aoki-Kinoshita, K. F., Dell, A., Narimatsu, H., York, W., Taniguchi, N., and Kornfeld, S. (2015) Symbol nomenclature for graphical representations of glycans. Glycobiology. 25, 1323-1324

76. Frishman, D., and Argos, P. (1995) Knowledge-based protein secondary structure assignment. Proteins. 23, 566-579

77. Crooks, G. E., Hon, G., Chandonia, J.-M., and Brenner, S. E. (2004) WebLogo: a sequence logo generator. Genome Res. 14, 1188-1190

\section{Abbreviations}

3'SL, 3'-sialyllactose; A, Angström; CD, catalytic domain; ConA, concanavalin A; DTconTS1, EndoH $\mathrm{f}_{\mathrm{f}}$ deglycosylated TconTS1; E., Escherichia; EndoH $\mathrm{H}_{\mathrm{f}}$, recombinant protein fusion of Endoglycosidase $\mathrm{H}$ and maltose binding protein; fs, femtosecond; $\mathrm{Gal}$, galactose; Glc, glucose; GlcNAc, N-Acetylglucosamine; HPAEC-PAD high performance anion exchange chromatography with pulsed amperometric detection; $\mathrm{K}$, Kelvin; kJ, kilo Joule; LD, lectin-like domain; MALDI-TOF, matrix-assisted laser desorption ionization time-of-flight; Man, mannose; MD, Molecular dynamics; MS, mass spectrometry; Neu5Ac, N-acetylneuraminic acid; nm, nanometer; ns, nanosecond; ps, picosecond; P., Pichia; SA, sialidase; Sia, sialic acid; $T$., Trypanosoma; TcruTS, Trypanosoma cruzi trans-sialidase; TconTS, Trypanosoma 
bioRxiv preprint doi: https://doi org/10.1101/2021.1213,472379; this version posted December 14,2021 . The copyright holder for this preprint (which was not certified by peer review) is the author/funder, who has granted bioRxiv a license to display the preprint in perpetuity. It is made available under aCC-BY 4.0 International license.

congolense trans-sialidase; TM, melting temperature; TranSA, Trypanosoma rangeli sialidase; TS, trans-sialidase; Trypanosoma vivax TvivTS; 3'SL, 3'sialyllactose

\section{Tables}

Table 1: Summary of MALDI-TOF MS analyses of the $\mathbf{N}$-glycan profile of TconTS1. Different highmannose-type $\mathrm{N}$-glycans were identified at potential $\mathrm{N}$-glycosylation sites of untreated TconTS1

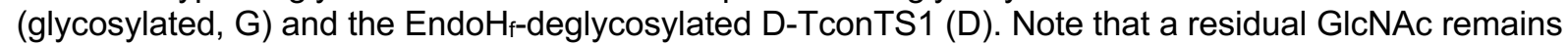
attached to the protein $\mathrm{N}$-glycosylation sites after EndoH $\mathrm{f}_{\mathrm{f}}$-cleavage. Branched glycans could still be

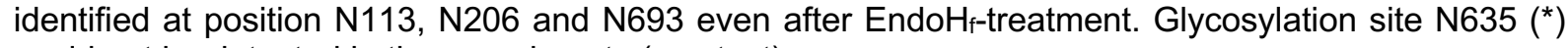
could not be detected in the experiments (see text).

\begin{tabular}{|c|c|c|c|c|c|c|c|c|c|}
\hline$N$-glycan & $\mathrm{N}_{45}$ & $\mathrm{~N}_{113}$ & $\mathrm{~N}_{206}$ & $\mathrm{~N}_{240}$ & $\mathrm{~N}_{281}$ & $\mathrm{~N}_{625}$ & $\mathrm{~N}_{635^{*}}$ & $\mathrm{~N}_{657}$ & $\mathrm{~N}_{693}$ \\
\hline Unglycosylated & & $G / D$ & G & G & & G / D & & & $G / D$ \\
\hline $\operatorname{Man}_{5} \mathrm{GlcNAc}_{2}$ & G & $G / D$ & $G / D$ & G & G & & & G & G \\
\hline $\mathrm{Man}_{6} \mathrm{GlcNAc}_{2}$ & & G & G / D & & & & & & $\mathrm{D}$ \\
\hline $\operatorname{Man}_{8} \mathrm{GlcNAc}_{2}$ & & & G / D & & & & & & \\
\hline $\mathrm{Man}_{5} \mathrm{GlcNAc}_{2}$ Fuc & & & G & & & & & & \\
\hline GlcNAc & $\mathrm{D}$ & $\mathrm{D}$ & G / D & $\mathrm{D}$ & $G / D$ & & & $\mathrm{D}$ & $\mathrm{D}$ \\
\hline
\end{tabular}

\section{Figures and figure legends}

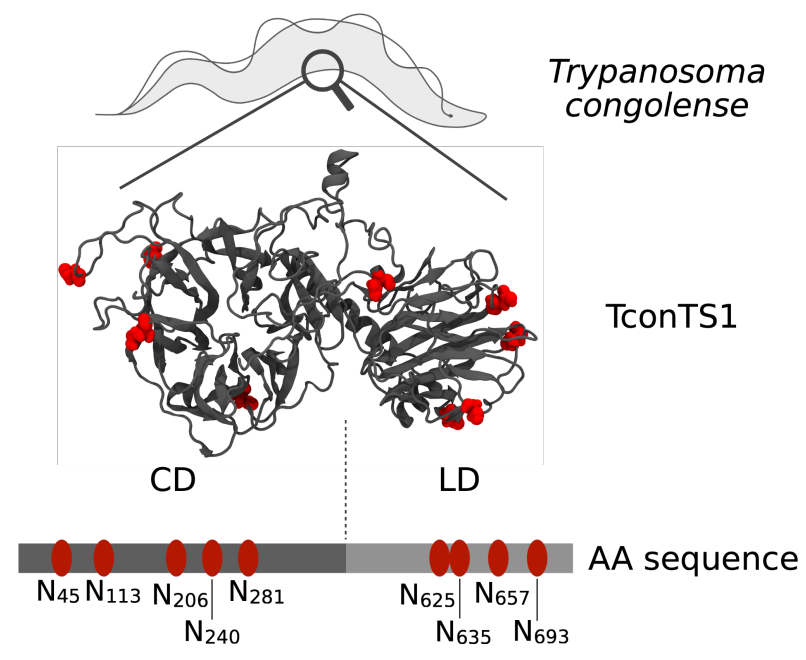

Figure 1. Molecular model of TS originating from Trypanosoma congolense (TconTS1) with Nglycosylation sites. Asparagine residues in the motif $N-X-S / T$ as putative $N$-glycosylation sites are highlighted in red. The positions of each asparagine are labelled in the amino acid sequence and sorted into the catalytic domain (CD) or the lectin-like domain (LD). 
A

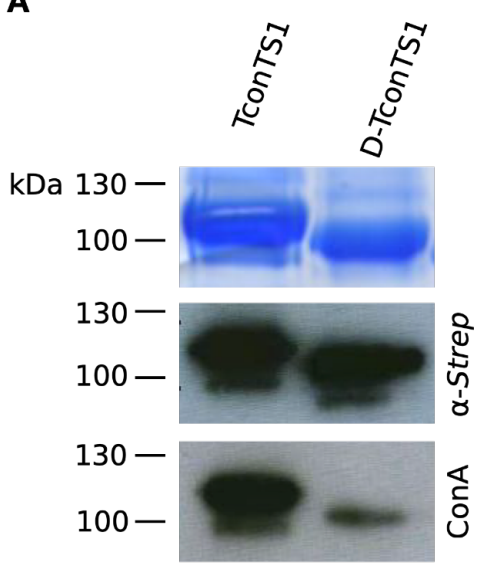

B

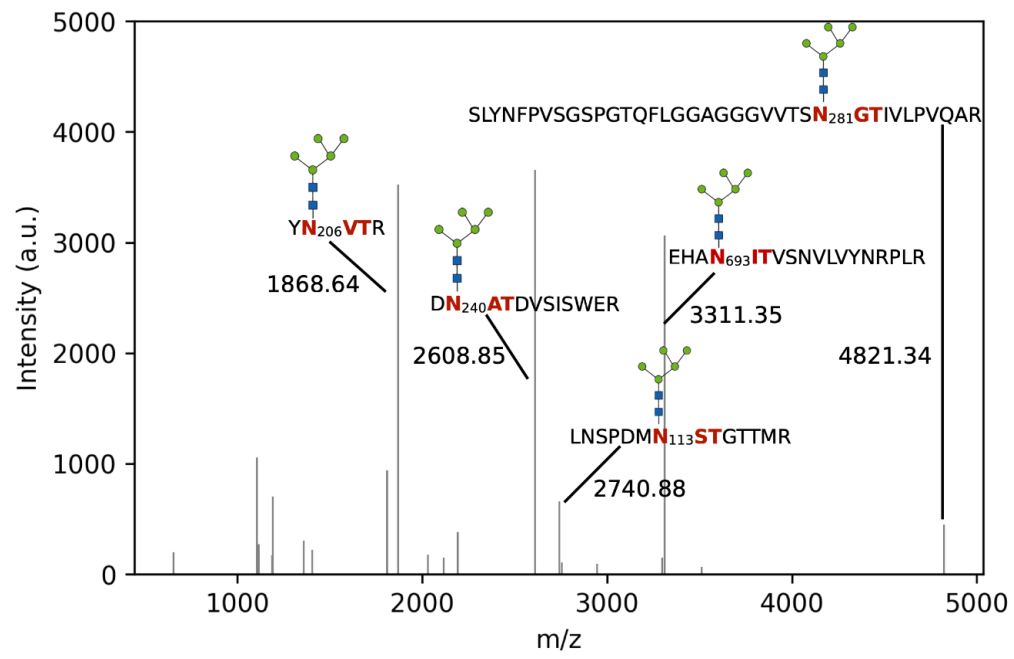

Figure 2. Mapping the $\mathrm{N}$-glycosylation profile of untreated (TconTS1) and deglycosylated TconTS1 (D-TconTS1). A) TconTS1 and D-TconTS1 were analyzed by SDS-PAGE with subsequent coomassie staining (upper panel), by Western blot analysis using an anti-Strep-tag antibody (middle panel) and by lectin blotting using ConA (lower panel). Results indicate the presence of high-mannose type $\mathrm{N}$-glycans. B) MALDI-TOF MS analyses were performed to identify $\mathrm{N}$-glycosylation sites of TconTS1. Glycopeptides from protease-digested TconTS1 were ConA-purified to concentrate glycopeptides and reduce the spectrum complexity. Peak lists were extracted from MALDI-TOF mass spectra, plotted with python and annotated with corresponding masses and glycopeptide fragments, respectively. Monosaccharide symbols follow the Symbol Nomenclature for Glycans (SNFG) (75).

A

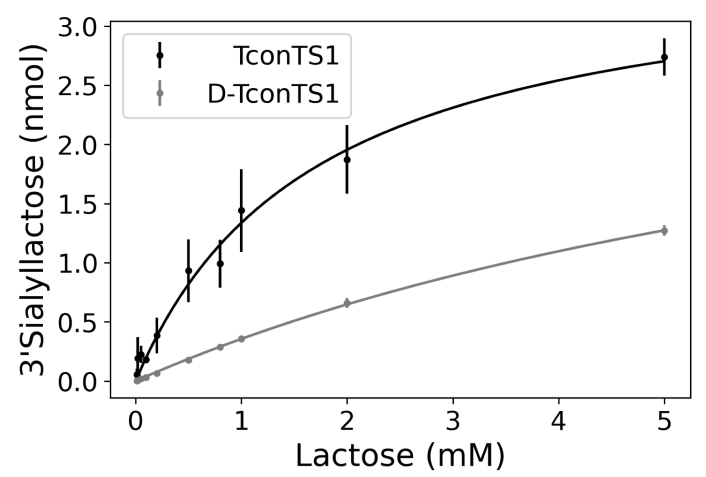

B

\begin{tabular}{ccc}
\hline & TconTS1 & D-TconTS1 \\
\hline $\begin{array}{c}\mathbf{V}_{\max } \\
(\mu \mathrm{mol} / \min x\end{array}$ & $2.42 \pm 0.17$ & $2.38 \pm 0.09$ \\
$\mathrm{mg}$ enzyme) & & \\
$\mathbf{K}_{\mathbf{M}}(\mathrm{mM})$ & $1.72 \pm 0.27$ & $9.05 \pm 0.45$ \\
\hline
\end{tabular}

Figure 3. EndoH $\mathrm{H}_{\mathrm{f}}$-treated D-TconTS1 shows lower substrate affinity compared to TconTS1, determined by Michaelis-Menten kinetics. A/B) TS activities for TconTS1 and D-TconTS1 were determined using fetuin as Sia donor and a lactose concentration series as Sia acceptor. Production of 3'sialyllactose was monitored and Michaelis-Menten kinetic parameters $K_{M}$ and $V_{\max }$ for lactose were evaluated using SigmaPlot11. Data points are means \pm standard deviation of three technical replicates. 
A

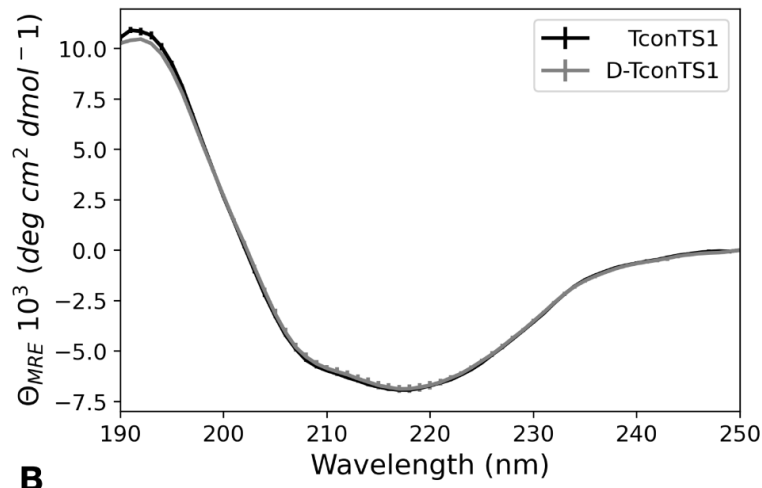

B

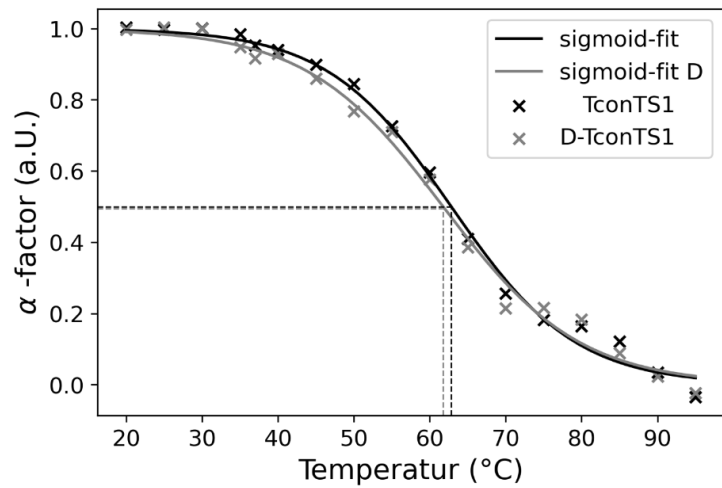

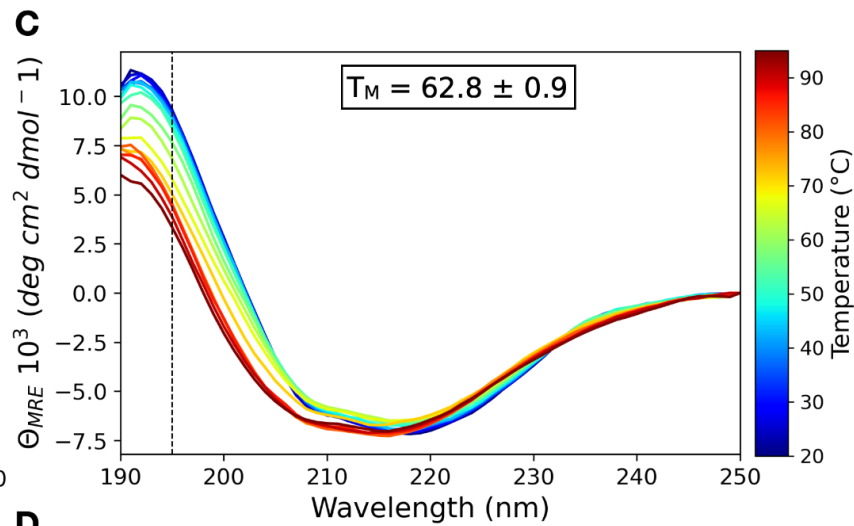

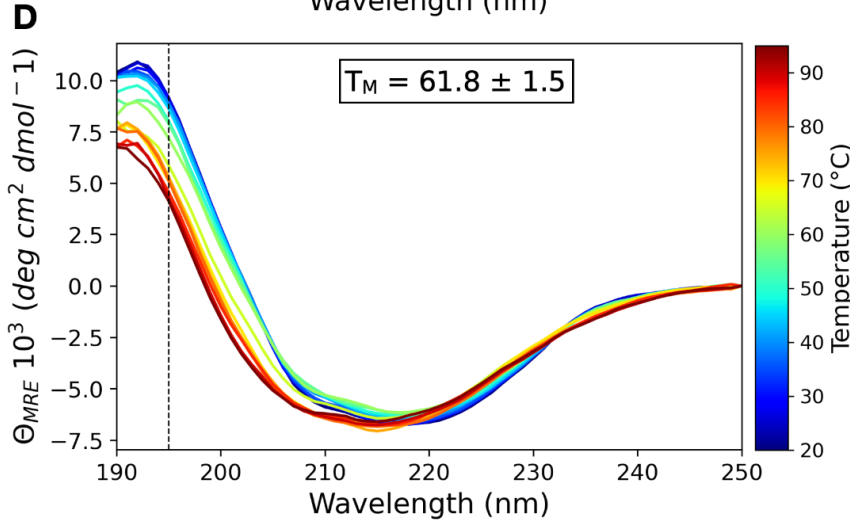

Figure 4. Influence of $\mathbf{N}$-glycans on TconTS1 secondary structure and stability. A) Circular dichroism spectra of untreated TconTS1 and EndoH $\mathrm{H}_{\mathrm{f}}$-treated D-TconTS1 were measured at $35^{\circ} \mathrm{C}$ in 10 $\mathrm{mM}$ phosphate buffer $\mathrm{pH} 7.4 \mathrm{~B})$ The midpoint of unfolding $\left(\mathrm{T}_{\mathrm{M}}=\alpha\right.$-factor $\left.=0.5\right)$ from a folded state $(\alpha-$ factor $\sim 1.0$ at $20^{\circ} \mathrm{C}$ ) to a partially unfolded intermediate ( $\alpha$-factor $\sim 0.0$ at $95^{\circ} \mathrm{C}$ ) were determined for TconTS1 and D-TconTS1 by fitting a sigmoid function to the data. Circular dichroism spectra of temperature-ramping experiments with TconTS1 (C) and D-TconTS1 (D) were recorded in $5^{\circ} \mathrm{C}$ steps and a 5 min equilibration time at each step. The midpoint of unfolding $\left(T_{M}\right)$ is determined at $195 \mathrm{~nm}$ (dashed line) at the flex point of a sigmoidal function fitting the temperature curve.

A

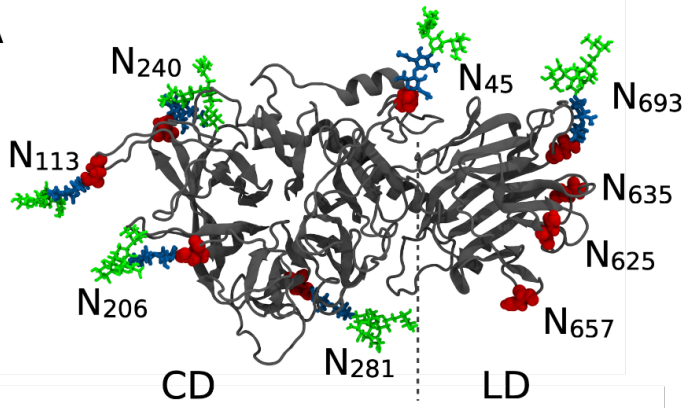

\section{C}

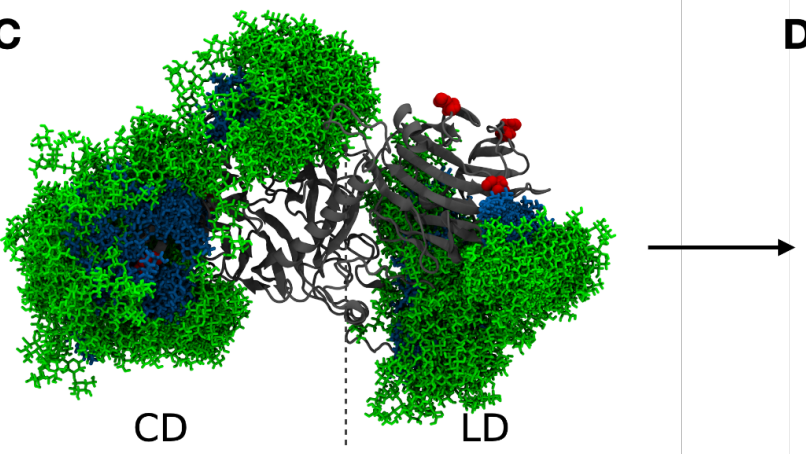

B

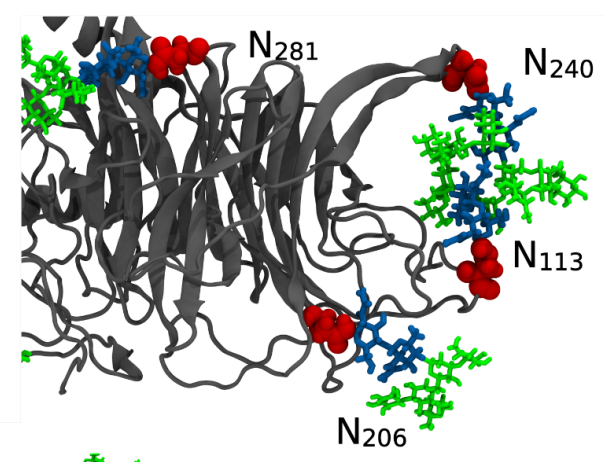

D

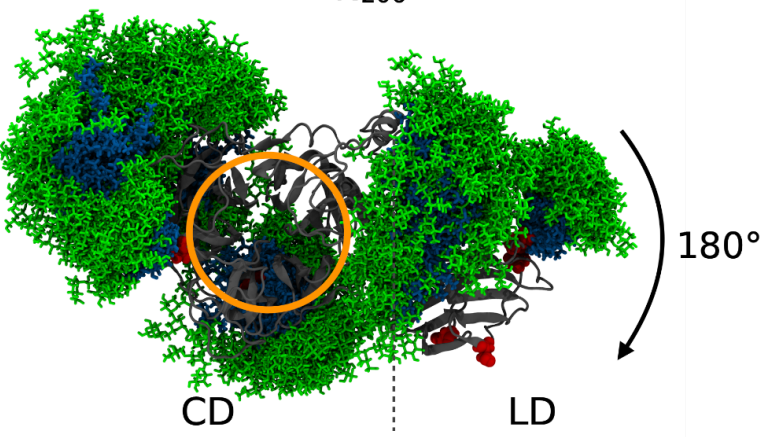


bioRxiv preprint doi: https://doi.org/10.1101/2021.12.13.472379; this version posted December 14, 2021. The copyright holder for this preprint (which was not certified by peer review) is the author/funder, who has granted bioRxiv a license to display the preprint in perpetuity. It is made available under aCC-BY 4.0 International license.

Figure 5. Analysis of the dynamics of TconTS1's $\mathbf{N}$-glycan shield. A) Atomistic model of TconTS1 with attached Man ${ }_{5} \mathrm{GlcNAc}_{2} \mathrm{~N}$-glycans (Man: green, GlcNAc: blue) at the asparagine residues (red) identified in MALDI-TOF MS experiments. B) Interactions between N240 and N113 glycans mediated by hydrogen bonds observed during the MD simulations. C) Overlay of all $\mathrm{N}$-glycan positions recorded every $5 \mathrm{~ns}$ over a simulation time of $500 \mathrm{~ns}$, with the protein backbone (grey) aligned in all frames. D) Same as C, with the protein rotated by $180^{\circ}$ and the active site indicated by an orange circle. The Cterminal SNAP-Strep is absent in all structures.
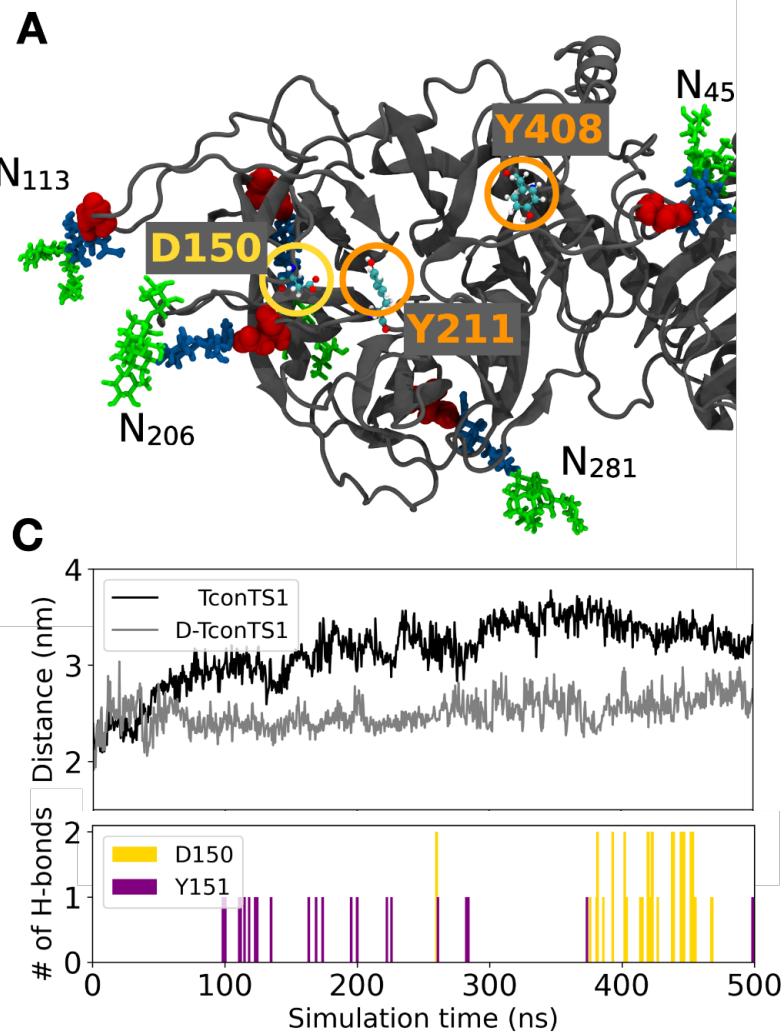

B

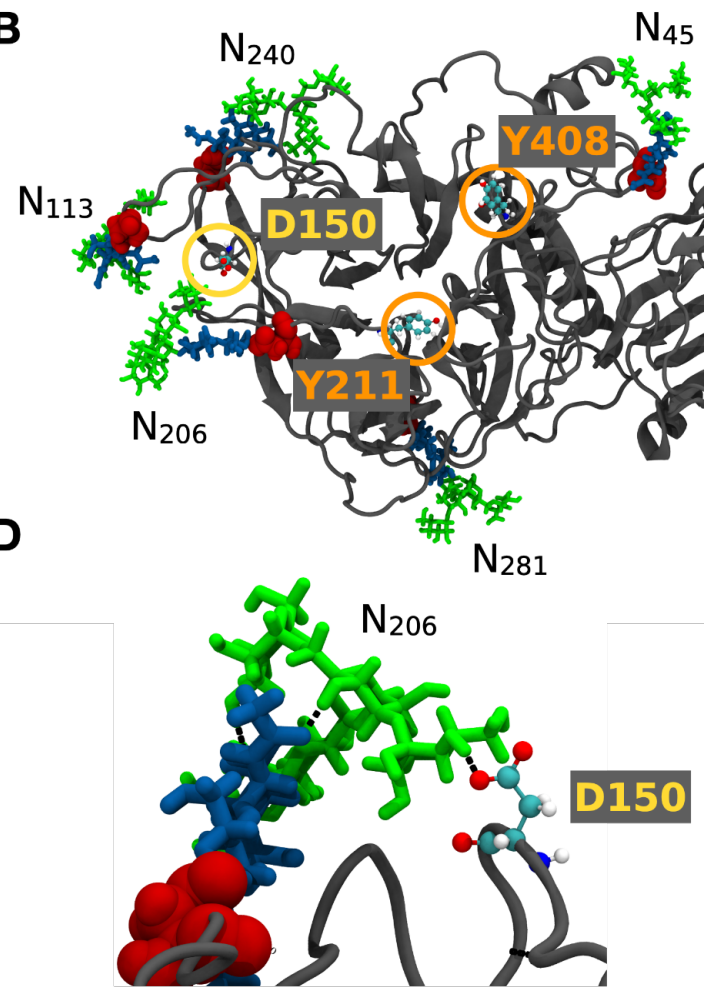

Figure 6. Protein-glycan interactions drive active site rearrangements observed in MD simulations of TconTS1 without substrate. A) Amino acids of the catalytic site were in close proximity at the beginning of the simulation (Snapshot at $100 \mathrm{~ns}$ ). B) D150 moved out of the catalytic site and formed hydrogen bonds with glycan N206 until the end of the simulation (Snapshot at $350 \mathrm{ns).} \mathrm{C)} \mathrm{Time}$ evolution of the distance between the center of D150 and the center of R410 for TconTS1 (black) and D-TconTS1 (grey) as well as numbers of hydrogen bonds for TconTS1 between glycan N206 and D150/Y151. For D-TconTS1, no hydrogen bonds were observed. D) Detail of the hydrogen bonds (black dashed lines) between D150 and glycan N206 at its terminal mannose branches. D150 is circled in yellow and the ligand-binding residues Y211 and Y408 are circled in orange and represented in balland-stick with the following color code: oxygen (red), carbon (cyan), nitrogen (blue), hydrogen (white). The underlying protein structure is represented in cartoon style in grey with asparagine residues of $\mathrm{N}$ glycosylation sites labelled in red spheres. Glycan color code: Man (green), GlcNAc (blue). 

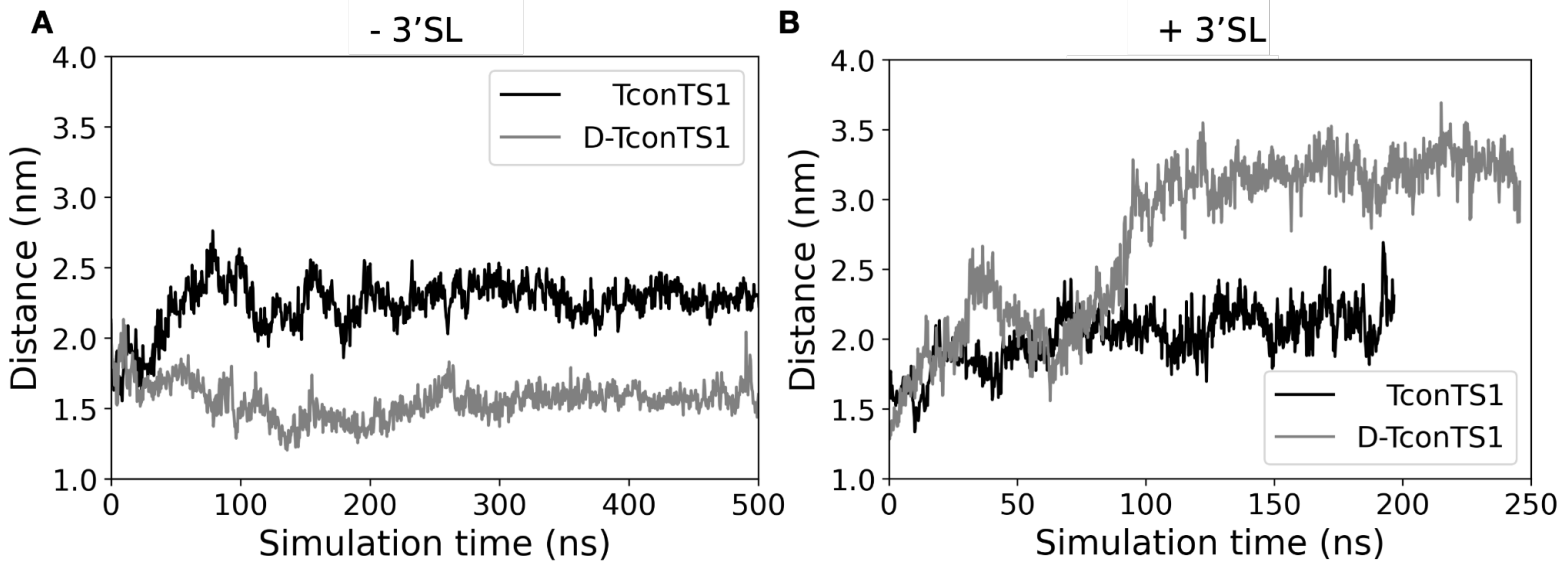

Figure 7: Altered movement of lactose holder amino acids in Endo $_{\mathrm{f}}$-treated D-TconTS1 compared to untreated TconTS1. Distance in nm between the $C_{\alpha}$ of $Y 211$ and $C_{\alpha}$ of $Y 408$ for TconTS1 (black) and D-TconTS1 (grey) measured over time in ns. A) Simulations without substrate. B) Simulations with substrate.

A

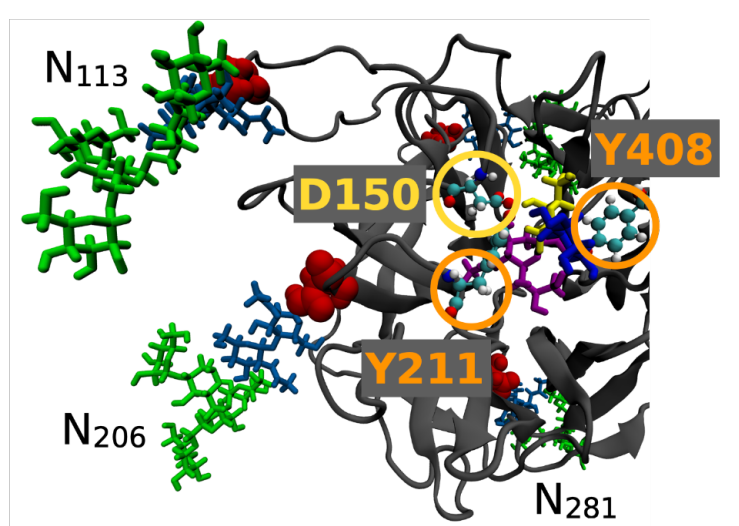

C

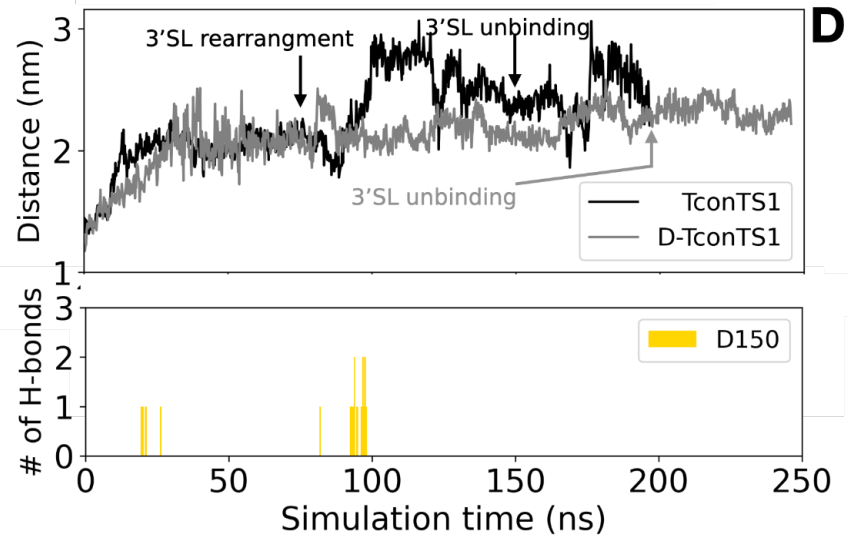

B

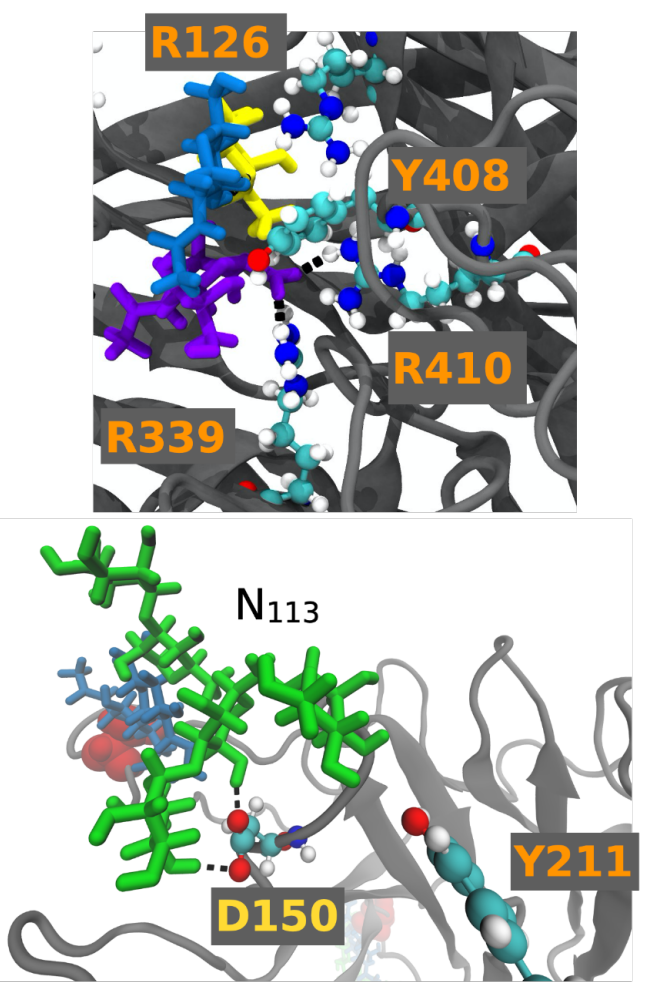

Figure 8. MD simulations of TconTS1 with 3'SL bound to the active center revealed proteinglycan interactions. A) Starting structure. B) Snapshot of 3'SL in the binding pocket, forming hydrogen bonds (black dashed lines) to conserved arginine residues. C) Distance between the center of D150 and the center of R410 for TconTS1 (black) and D-TconTS1 (grey). Number of hydrogen bonds between D150 and glycan N113 for TconTS1 over the course of the simulation. D) D150 interacts with glycan $\mathrm{N} 113$ via hydrogen bond formation (black dashed lines) at its mannose branches (snapshot at $97 \mathrm{~ns}$ ). Color code of the amino acids as in Fig. 6. Glycan color code: Man (green), GlcNAc/Glc (blue), Gal (yellow), Neu5Ac (violet). 